\title{
A HYBRID APPROACH TO INVESTIGATE THE RELATIONSHIP BETWEEN DESIGN FACTORS AND SUSTAINABILITY
}

\author{
Elahe Mohagheghian®, Hasan Hosseini-Nasab*๑, Yahia Zare-MehrJerdi \\ AND MOHAMmad-Bagher FAKHrZAD®
}

\begin{abstract}
Factors considered in product design have a significant impact on future cost and sustainability. Some factors such as materials, dimensions, and tolerances are crucial in the design process of many products. At the macro scale, this can give rise to environmental effects and influence the reliability and sustainability of the product. In this research, a hybrid system dynamics simulation-optimization approach has been proposed for tolerance design. In this approach, first, the optimal values of tolerance and price are determined by conjoint analysis. These values are entered into a system dynamics model to evaluate the relationships among sustainability, reliability, and customer satisfaction. Then, the impact of tolerance and other factors of product design on sustainability, reliability, and customer satisfaction are investigated. This approach can help decision-makers better understand the trade-off between design factors, resilience, sustainability, and customer satisfaction and make more informed decisions. The proposed method is illustrated for computer assembly step by step. The results show that lower sustainability and higher customer satisfaction are directly associated with tighter tolerances. Besides, lower sustainability, higher reliability, and higher customer satisfaction are associated with lower quality of materials. The validity of the model was examined using a boundary-adequacy test.
\end{abstract}

Mathematics Subject Classification. 05B10, 60K10.

Received July 30, 2021. Accepted August 23, 2021.

\section{INTRODUCTION}

The use of industrial products has risen dramatically in the world. Sales figures of many products reveal a surge in their production and sales. Product users, as stakeholders, usually make purchase decisions based on pre-defined features. Price and dimensional tolerances are among attributes that are primarily determined by the manufacturers. Previous studies suggest that customers care about products that are environmentally friendly and are willing to pay a higher price for such products, so customers look for products that meet their requirements. The manufacturers' knowledge of customers' requirements can contribute to the perfect design of a product. Large manufacturing companies utilize various methods to gain insights into customer demands.

Given the variety of products and the competitiveness of the market, manufacturers have to take action to select appropriate attributes and slash prices for their survival. Today, the best quality of a product is

Keywords. Conjoint analysis, system dynamics, design factors, sustainability, reliability.

Department of Industrial Engineering, Yazd University, Yazd, Iran.

* Corresponding author: hosseininasab@gmail.com 
not adequate to ensure an organization's survival, but a manufacturer must also consider other factors such as sustainability and reliability. It should be noted that there is no simple way of linking tolerances to their consequences, but is possible to present some functions that can relate tolerances to sustainability and reliability factors in the product life. In this regard, issues such as the production of environmentally friendly products with the lowest cost and zero waste, continuous cost reduction, design and manufacture of highly reliable products, and no need for repairs are of particular importance. Previous studies suggest that dimensional tolerance, as one of the attributes of the new product, can have a significant effect on product sustainability and reliability. For example, tolerance values are directly associated with production costs, and this relationship has been the subject of extensive research in recent decades $[29,38,39]$. Improper tolerances may gradually provoke unanticipated disruptions in a product, increase the likelihood of premature failure and affect its reliability and other costs.

The bulk of studies reveal that determining the optimal values of tolerances minimizes production or repair costs. These studies aim to minimize costs based on a set of predetermined tolerance values but fail to provide a profound analysis of how sustainability and reliability factors affect demand and customer satisfaction. In other words, in demand and market share functions, sustainability and reliability factors are not formulated according to the product tolerance features. Hence, it is necessary to investigate the relationship between these variables. Given that these variables are interdependent, i.e., changes in one factor triggers changes in others, designers look for methods that can capture their complex and dynamic relationships in the short and long terms and demonstrate feedback relationships. For example, the need to repair a computer or its reliability can disrupt customer programs, reduce their satisfaction and consequently diminish future market demand. Such cases, which involve complex relationships between variables, and feedback loops have to be modeled by proper methods.

On the other hand, considering the concept of reliability at the stage of product design can increase customer satisfaction, and ultimately, augment a larger customer demand. To the best of our knowledge, this concept has not been investigated in the sustainable product design literature.

In this study, the hybrid methodology is proposed to determine the optimal tolerance, price, and the relationships between different factors in the scope of product design. To this end, a hybrid decision-making framework including conjoint analysis and system dynamics has been used. Conjoint analysis was first developed in the early 1970s and has since been employed by many manufacturers to explore the attributes of new products such as tolerance and pricing and to maximize market share and sales. System dynamics is one of the most effective approaches that manifest system behavior by considering complex relationships between different variables as well as feedback loops and delays. Simulating variables and determining their causal relationships provides deeper insights for decision-makers to manage the market under a specific planning horizon.

Accordingly, this paper utilizes conjoint analysis as the market research method to estimate key variables. Optimal tolerance values, product demand, and price are the main outcomes of conjoint analysis. In fact, conjoint analysis shows how to optimize tolerance as one of the major design decisions in the market, revealing how these decisions can influence important customer metrics, such as reliability, environmental friendliness, and price. Then, a system dynamic approach is proposed to explore the relationships between different parameters of product design, reliability, sustainability, and customer satisfaction based on a number of scenarios. First, the procedure of conjoint analysis and system dynamics are determined in order to improve the formulations of the system dynamics model. Then, the conjoint analysis results are discussed in order to assess the main inputs of the system dynamics approach. Finally, using the system dynamics modeling approach, the complex interaction between different variables is investigated and the results are analyzed. In the end, the proposed framework for computer production is discussed. The primary concentration is on the sustainability factors and reliability of the product. In summary, the main contributions of the current study are as follow:

- Investigating the relationship between reliability, product design, and sustainability to increase customer satisfaction; 
- Providing a hybrid simulation-optimization model based on factors of product sustainability and reliability, which also affect product design factors as well as new optimization model including conjoint analysis, market share development, profit maximization, and solution algorithm;

- Providing a new system dynamics simulation model to assess the relationship between reliability, product design, and sustainability to increase customer satisfaction and the impact of factors on each other.

\section{BACKGROUND AND LITERATURE REVIEW}

\subsection{Background}

To motivate the methodology applied in this research, the following sub-sections consider some background on the relevant research. First, specific concepts modeled in this study are described, particularly tolerance and variation analysis, as design factors influencing product reliability, and environmental impacts. Next, environmental sustainability is discussed to establish the relevance of the product design scenarios proposed in this paper. Afterward, an overview of conjoint analysis and profit maximization is presented. Finally, an overview of system dynamics is provided.

\subsubsection{Tolerance and variation analysis}

The difference between the minimum and maximum permissible variations from the limit size is known as tolerance. Tolerance determines acceptable dimensions for a product. To fabricate a spare part or a product, all dimensions must have certain tolerances. Proper tolerance control by the designer can reinforce the efficiency of the production line and ensure the quality of manufactured parts. By investigating design and production factors, it is possible to reduce costs associated with product failure and improve business competitiveness [16].

Determining the permissible tolerance in specifications depends not only on the desired attributes of the product but also on the capacity of the production process. Tolerance specifies simultaneously the accuracy of production, and the performance of that part. Prerequisites for accurate production are a precise method, and a skilled labor force, which increases the production costs [35]. These can affect the manufacturing processes chosen, time and cost of manufacturing, and the amount of waste generated during the production, which is a sustainability concern. Conventional approaches to tolerance optimization involve minimizing production costs; hence, there is usually an inverse relationship between costs and tolerances.

\subsubsection{Environmentally impacts}

A product has significant impacts on the ecological system during its life cycle. Some of these effects are of little significance while others may affect a broad breadth of geographical factors (e.g., global warming). For this reason, in recent years, consumers have dedicated growing attention to the environmental aspects and the effects of products. A growing number of people are willing to pay more for environmentally friendly products. Manufacturers have realized that considering environmental considerations in the design and development of products could be beneficial.

The benefits include reduced costs, improved product reliability, and greater market competitiveness. Such environmental concern involves selecting recoverable materials and determining the appropriate range for tolerance. The proper estimation of tolerance range for the designed parts can affect the environment by reducing the number of discarded products, the number of early product failures, and maintenance and repair costs [18]. Other factors such as materials and end-of-life strategies may have profound environmental impacts. To gain insights into the role of design decisions in the product reliability and sustainability, the present study explores these links by examining consumer preferences from the system dynamics approach.

\subsubsection{Conjoint analysis}

Conjoint analysis, as one of the crucial multivariate techniques, is used specifically to figure out how customers express their desire for products. The application of this technique in market research dates back to the late 1980s, and significant advances have been made in its methodology to date. This technique has been employed 
to study the market of many industrial products in developed countries [14]. The basic premise of the conjoint analysis is that a product can be broken down into its constituents. For example, a computer has attributes such as price, tolerance, recyclable materials, memory, screen size, etc. The utility of a product is estimated by combining the utility of each attribute of that product. The purchase intention of a product is dependent on the profit derived from that product. The utility is a numerical expression of the value that customers attach to an attribute, which indicates its relevant value.

\subsubsection{Profit maximization}

The profit per unit of a product can be calculated by subtracting the manufacturing cost per unit from its sale price. Therefore, the total value of $\pi$ is obtained by multiplying the profit per unit of a product by the market demand, $D$. This mathematical function is the objective that many enterprises seek to maximize:

$$
\pi=D(p r-c) \text {. }
$$

For the desired product design, environmental effects, reliability, and other factors that are likely to impact the pricing must be considered. In this regard, mathematical models associated variables with goals and constraints. Several optimization algorithms have been developed to solve such problems, the most notable of which are gradient-based algorithms such as Sequential Quadratic Programming (SQP) [34].

Optimizers can select gradient-based algorithms for nonlinear functions. These methods are effective and their effectiveness in tackling various types of optimization problems has been demonstrated. However, these methods suffer from drawbacks, such as local minimum traps, and computational complexity in some objective functions. This has created the need for developing a new type of solution that can address these shortcomings. In this study, a Derivation-Free Global Search algorithm (DFGS) have been used as a suitable tool for optimization that can overcome most of the limitations associated with gradient-based methods [22].

\subsubsection{System dynamics}

The system approaches were first applied to supply chains by Forrester [9] in the 1950s, and since then, have been widely used for different supply chains. System dynamics is a way of thinking that allows understanding the input-output relationships, and nonlinear behavior of systems over time using stocks, flows, table functions, and time delays [10]. A typical procedure for modeling system dynamics is to (1) identify and define the problem, (2) portray the systems, (3) develop a computer simulation, (4) illustrate the outcomes, and (5) define potential policies. The following explains the steps to manufacture a computer product to clarify the proposed model.

\subsection{Literature review}

Given the emphasis of manufacturers on customer satisfaction, extensive research has been undertaken on the design, and production of various products. Proper product design can boost the profitability and market share of each manufacturer. Design features are usually determined by customer requirements. Therefore, identifying consumer preferences of product features is a fundamental design requirement. There are diverse ways to identify consumer preferences for products on the market. Due to the wide variety of products in consumer markets, all decisions on product design should be aimed at maximizing market share. Conjoint analysis is a well-known approach that identifies consumer preferences through surveys.

Aydin et al. [4] investigated the market share of products using the conjoint analysis method. They performed a case study on the coordination of supply chain members in designing personal computers to demonstrate the application and effectiveness of the proposed method. In this study, a multi-objective optimization model based on Stackelberg game theory is formulated to determine design decisions, price, and product return rate for re-manufacturing. Alp and Öz [1] studied features such as memory, graphics, processor model, storage type, screen size, and operating system for conjoint analysis in the laptop market. These attributes are the main parameters considered by the staff of Yildiz Technical University for making a laptop purchase decision. The results of their analysis suggested that the processor model had the top priority, followed by specifications such as memory capacity, operating system, storage type, graphics card, and screen size, respectively. 
Kuzmanovic et al. [23] presented a model for maximizing the profitability of designing a competitive product line in a heterogeneous market. In conjoint analysis, the preferences were modeled using part-worth utilities associated with the levels of relevant attributes, and a logit model was employed to convert the respondents' preferences into a potential market share. Finally, the product line optimization problem was formulated as nonlinear binary programming. The proposed model was tested using a previously published dataset and its efficiency and application were assessed.

Zeballos et al. [45] addressed product design by examining the attributes of new products and remanufacturing. The goal of this study was to maximize total profit relative to design features, and the sale price of new and remanufactured products, considering that consumer preferences rely on the features and price of products. In this study, life cycle benefits and environmental effects were also considered and the product was designed by the MILP method. Finally, the model behavior was evaluated using computational tests on a desktop computer. Many features have to be taken into account for product design along with economic and environmental aspects of the product. Alternatively, different analysis tools could also be used for exploring the attributes of new products such as latent class or nested logit analysis. However, such techniques have not yet been proven to improve utility estimate accuracy, and require uncertainties, and assumptions [37].

Various interactions and complex connections between variables highlight the importance of using simulation tools. System dynamics, as a simulation tool, help model complex problems seamlessly. Hoffenson and Soderberg [17] proposed a system thinking model to predict the impact of design decisions on future design decisions in Japan. In this paper, those design decisions that influenced product quality were presented in a system thinking framework along with hypotheses for a mobile phone case. A more recent study on product design was conducted in China [44]. It looked at mobile phone management and waste recycling using an integrated method of life cycle assessment and system dynamics. In addition, three key factors of sustainability (resources, human health, and ecosystem quality), which are significantly affected in this process, were considered. Then, a system dynamics model was developed to examine the effects of different recycling rates.

To illustrate the system dynamics approach, Lee et al. [24] studied the public bicycle system as a case study to measure sustainability using a holistic perspective. In this paper, some indices were defined for all three dimensions to measure the sustainability of the public bicycle system. They defined two indicators of "resource exploitation", and "emission of pollutants" for the environmental sustainability. For economic sustainability, the economic benefits of each stakeholder were taken into account. Stakeholders included users, public bicycle system operators, bicycle retailers, and local bus companies. Finally, "human health" was also considered as an important social index among various indices associated with public welfare. Then, based on these factors, they identified simple causal relationships in each dimension of sustainability.

Liu et al. [25] focused on the sustainable design and production in an attempt to develop a dynamic system model. They explored the relationship between design, manufacturing, and sustainability. This paper conducts a pilot study using the system dynamics model, in which the relationship between design and manufacturing is determined in terms of sustainability. Using the system dynamics method, this study investigated the association between variables through expert interviews to estimate soft variables, and evaluate sustainable development methods. Through system dynamics analysis and the analysis of the relationship of design and manufacturing concepts with sustainable development approach, two key variables (design concept and construction technology) were explored by experts. The results revealed the positive impact of a design concept and manufacturing technology on the sustainable development.

In a study by Alamerew and Brissaud [2], the interactions of economic, social, and environmental sustainability factors were studied using system dynamics modeling with the aim of modeling and evaluating product recovery strategies. In addition, a case study on waste electrical and electronic equipment was presented to validate the proposed model. This model was developed for policymakers who continually improve their decisions and set their future goals for the management of End-Of-Life (EOL) products. Further simulation tools could also be used to investigate the relationship between different factors. In a study by Asif et al. [3], the interactions of design factors, and sustainability were studied using a multi-method simulation model composed of system dynamics and agent based principles. 
According to mentioned literature, although the previous studies have explored the subject, none of them applied the proposed approach of this paper. Some researchers have used hybrid methods [3] or widely used one method for optimization or simulation $[1,4,23,37,45]$. Only a few studies have considered the sustainability factors, and none of them has addressed the reliability factor of the product. The main contributions of this research can be listed as follows:

- Providing a new hybrid simulation-optimization model based on sustainability factors and product reliability, which affect product design factors and a new optimization model including conjoint analysis, market share development, profit maximization, and solution algorithm.

- Providing a new system dynamics simulation model to assess the relationship between reliability, product design, and sustainability as well as the impact of factors on each other.

- Investigating the relationship between reliability, product design, and sustainability to increase customer satisfaction.

A more detailed classification of the literature is presented in Table 1, concerning six features including the sustainability factors, reliability, product design factors, scope, industry, and method. The features related to the problem in the present study are presented in the last row of the table.

\section{Problem DESCRIPTION}

In the product design, the products are investigated based on the defined attributes and attribute levels. In this study, the related attributes to the research goals are price, reliability, and environmental impacts, which will be considered as a function of discard rate. Additionally, one of the design factors (e.g., tolerance) affects the amounts of product discard rates. By performing the steps of conjoint analysis step by step, it is possible to estimate utility functions that exist for each of the related attributes to the research goals (e.g., price, reliability and environmental impacts), and then by placing them on the discard rates in the market share as well as considering some other information (e.g., competitive products' information, estimated market potential), the market demand can be calculated.

Then, a profit function can be estimated as a function of market demand, price, and manufacturing costs. In this study, manufacturing costs are also considered as a function of discard rate. Consequently, considering variables such as reliability, environmental impacts, and manufacturing costs, as a function of tolerance, the profit function can be optimized based on the two variables of tolerance, and the product price. These optimal values of tolerance and price can be considered as input variables for the dynamic simulation model to examine the relationship between design factors, reliability, and sustainability. The study of these relationships with a hybrid approach is presented for the first time, and is shown in Figure 1.

For more elaboration, in the proposed method, the optimization process includes conjoint analysis, development of market share models, formulation of an optimization model, and a solution method. Conjoint analysis is conducted to design the market share function for attaining more reliable outcomes. The conjoint analysis can be done by utilizing a survey to capture preferences for different products based on the defined attributes. From this step, the relationship of price, reliability, and environmental impacts with tolerance and profit optimization is obtained. Based on these values, the discard rate or the percentage of products that must be excluded due to component incompatibility, as well as the reliability of the product and environmental impacts could be calculated. The values obtained at this stage can be used to determine the appropriate range for tolerance, depending on the number of products that needs to be reworked, the number of waste products, and the environmental impacts. Next, by implementing other steps of the conjoint analysis method, the utility functions of price, reliability, and environmental impacts are estimated through statistical regression. After determining the utility functions, the market share function is formulated. The market potential is also evaluated based on the experts' judgment. After developing market share models and estimating market potential, the demand model can be developed for the market. At the same time, based on the cost and price of each product unit, a one-objective optimization model will be solved by an optimization algorithm. 
TABLE 1. Summary of related literature.

\begin{tabular}{|c|c|c|c|c|c|c|c|c|}
\hline \multirow[t]{2}{*}{ Reference } & \multicolumn{3}{|c|}{$\begin{array}{l}\text { Sustainability } \\
\text { factors }\end{array}$} & \multirow{2}{*}{ 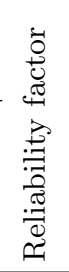 } & \multirow{2}{*}{$\begin{array}{l}\text { Product design } \\
\text { factors }\end{array}$} & \multirow[t]{2}{*}{ Scope } & \multirow[t]{2}{*}{ Industry } & \multirow[t]{2}{*}{ Method } \\
\hline & 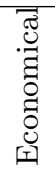 & 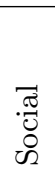 & 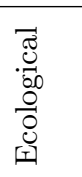 & & & & & \\
\hline Aydin et al. [4] & - & - & - & - & $\begin{array}{l}\text { Design } \\
\text { decisions, price, } \\
\text { and product } \\
\text { return rate }\end{array}$ & Supply chain & $\begin{array}{l}\text { Personal } \\
\text { computer }\end{array}$ & $\begin{array}{l}\text { Conjoint analysis } \\
\text { and optimization } \\
\text { model }\end{array}$ \\
\hline Alp and Öz [1] & - & - & - & - & $\begin{array}{l}\text { Product } \\
\text { attributes }\end{array}$ & $\begin{array}{l}\text { Product } \\
\text { design }\end{array}$ & Laptop market & Conjoint analysis \\
\hline $\begin{array}{l}\text { Kuzmanovic } \\
\text { et al. }[23]\end{array}$ & - & - & - & - & $\begin{array}{l}\text { Designing a } \\
\text { product line }\end{array}$ & $\begin{array}{l}\text { Product } \\
\text { design }\end{array}$ & $\begin{array}{l}\text { Dataset } \\
\text { previously } \\
\text { published }\end{array}$ & $\begin{array}{l}\text { Conjoint analysis } \\
\text { and optimization } \\
\text { model }\end{array}$ \\
\hline $\begin{array}{l}\text { Zeballos et al. } \\
\text { [45] }\end{array}$ & - & - & $\checkmark$ & - & $\begin{array}{l}\text { Product } \\
\text { attributes and } \\
\text { sale price of new } \\
\text { products and } \\
\text { re-manufacturing }\end{array}$ & $\begin{array}{l}\text { Product } \\
\text { design }\end{array}$ & $\begin{array}{l}\text { Desktop } \\
\text { computer }\end{array}$ & $\begin{array}{l}\text { optimization } \\
\text { model }\end{array}$ \\
\hline $\begin{array}{l}\text { Siriwardena } \\
\text { et al. }[37]\end{array}$ & - & - & $\checkmark$ & - & - & $\begin{array}{l}\text { Product } \\
\text { design }\end{array}$ & Green car & $\begin{array}{l}\text { Nested-logit anal- } \\
\text { ysis }\end{array}$ \\
\hline $\begin{array}{l}\text { Hoffenson } \\
\text { and } \\
\text { Soderberg [17] }\end{array}$ & $\checkmark$ & $\checkmark$ & $\checkmark$ & - & - & $\begin{array}{l}\text { Product } \\
\text { design }\end{array}$ & Mobile phone & $\begin{array}{l}\text { System thinking } \\
\text { model }\end{array}$ \\
\hline Yao et al. [44] & $\checkmark$ & $\checkmark$ & $\checkmark$ & - & - & $\begin{array}{l}\text { Product } \\
\text { design }\end{array}$ & Mobile phone & $\begin{array}{l}\text { System dynamics } \\
\text { model }\end{array}$ \\
\hline Lee et al. [24] & $\checkmark$ & - & $\checkmark$ & - & - & $\begin{array}{l}\text { Product } \\
\text { design }\end{array}$ & $\begin{array}{l}\text { Public bicycle } \\
\text { system }\end{array}$ & $\begin{array}{l}\text { System dynamics } \\
\text { model }\end{array}$ \\
\hline Liu et al. [25] & - & - & - & - & - & $\begin{array}{l}\text { Product } \\
\text { design }\end{array}$ & pilot study & $\begin{array}{l}\text { System dynamics } \\
\text { model }\end{array}$ \\
\hline $\begin{array}{l}\text { Alamerew and } \\
\text { Brissaud [2] }\end{array}$ & - & - & - & - & - & $\begin{array}{l}\text { Product } \\
\text { design }\end{array}$ & $\begin{array}{l}\text { electrical } \\
\text { equipment }\end{array}$ & $\begin{array}{l}\text { System dynamics } \\
\text { model }\end{array}$ \\
\hline Asif et al. [3] & $\checkmark$ & - & $\checkmark$ & - & $\begin{array}{l}\text { Product } \\
\text { attributes }\end{array}$ & $\begin{array}{l}\text { Product } \\
\text { design and } \\
\text { Supply chain }\end{array}$ & - & $\begin{array}{l}\text { Agent Based and } \\
\text { System dynamics } \\
\text { model }\end{array}$ \\
\hline This research & $\checkmark$ & - & $\checkmark$ & $\checkmark$ & $\begin{array}{l}\text { Product } \\
\text { attributes, Price }\end{array}$ & $\begin{array}{l}\text { Product } \\
\text { design }\end{array}$ & Computer & $\begin{array}{l}\text { Conjoint } \\
\text { analysis, } \\
\text { optimization } \\
\text { model, and } \\
\text { System dynamics }\end{array}$ \\
\hline
\end{tabular}

Additionally, for the macro-level modeling of the problem, a system dynamics simulation model is utilized by considering the main outputs of the optimization model (price and tolerance) and a combination of causal relationships. Using Vensim software, this model illustrates the interactions of different design factors, product reliability, sustainability factors, and customer satisfaction in the real world over a given planning horizon based on some scenarios. The details of the proposed hybrid method are described for a computer as a case study in the following sections. To describe the problem, a symbols list is presented in Table 2. 


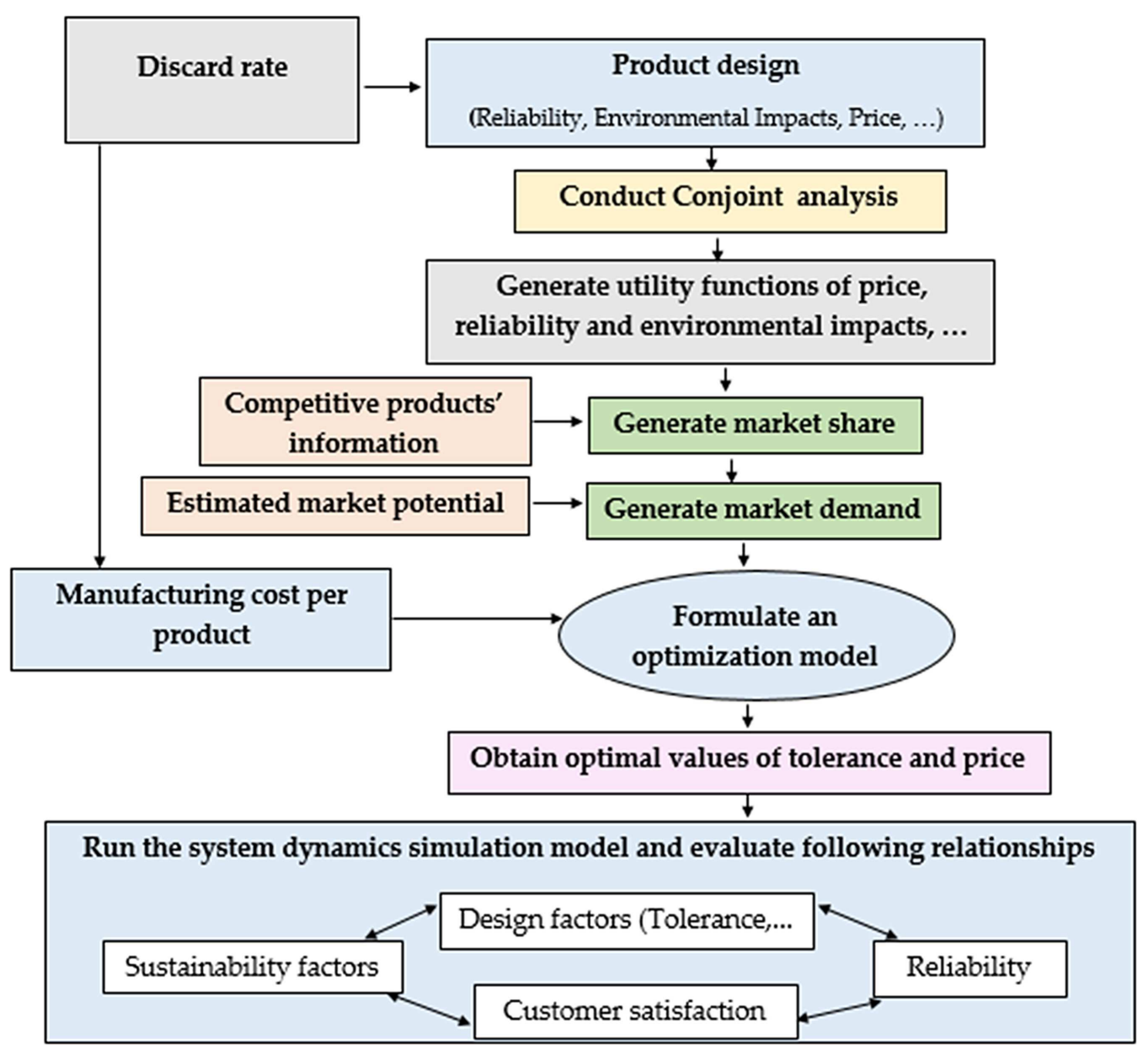

FiguRE 1. Flowchart of the hybrid optimization-simulation method.

\subsection{Discard rate}

For a product like a computer, the tolerances embedded in the place of the screws connecting the case, could be mentioned, which embrace the permissible values of variation from the nominal dimensions of the screws. Based on these values, the discard rate or percentage of products that have to be excluded due to the component incompatibility, as well as the reliability and environmental impacts could be calculated. Therefore, determining the tolerance range of the designed parts by reducing the number of discarded products, the number of early product failures, and the maintenance requirements, can be identified as determinants of product reliability, and environmental friendliness. Given that simulations used to calculate variables such as product reliability, environmental impacts are based on the discard rate of the new product $j\left(\varphi_{j}\right)$, we considered the Monte Carlo examples for the discard rate in a random manner in order to compute various values of $\varphi_{j}$, as a function of tolerance, $t_{j}$. To determine the appropriate level of discard rate, the experiments are designed based on a defined number of input tolerances in a certain range in each run of the Monte Carlo simulation. Assigning a large number of Monte Carlo simulations to each value of input tolerance can improve the reliability of results. In this study, survey data are used to calculate the desired level of allowable variation in critical dimensions or the percentage of products that have to be discarded due to the component incompatibility. 
TABLE 2. Symbols list.

\begin{tabular}{|c|c|}
\hline Indices & \\
\hline$i$ & Index for product profiles $i \in\{1,2, \ldots, I\}$, \\
\hline$j$ & Index for the new product $j \in\{1,2, \ldots, J\}$ \\
\hline$k$ & Index for competitive products $k \in\{1,2, \ldots, K\}$, \\
\hline$v$ & Index for attributes $v \in\{1,2, \ldots, V\}$ \\
\hline$l_{v}$ & The potential levels for each attribute $l_{v} \in\left\{1,2, \ldots, L_{v}\right\}$. \\
\hline \multicolumn{2}{|l|}{ Parameters } \\
\hline$\alpha_{j}$ & Environmental impacts of the raw materials per weight of the new product $j$ \\
\hline$\beta_{j}$ & Environmental impacts of the used materials in the production process per weight of the new product $j$, \\
\hline$\gamma_{j}$ & Disposal-related environmental impacts per weight of the new product $j$, \\
\hline$H_{j}$ & Fixed material cost of the new product $j$ \\
\hline$Z_{j}$ & Variable material cost increases the reliability of the new produced product $j$, \\
\hline$s_{j}$ & Recovery cost per weight of the new product $j$ \\
\hline $\operatorname{mass}_{j}$ & Quantity of the raw material of the product $j$ \\
\hline $\operatorname{proc}_{j}$ & Quantity of the materials used in the production process of the new product $j$, \\
\hline$Q^{-J}$ & Estimated market potential, \\
\hline$\rho$ & Discount factor, \\
\hline$r_{j}$ & Weight of parts to be recovered per unit of the new product $j$, \\
\hline $\mathrm{TT}_{j}$ & Expected life of the product $j$ \\
\hline $\mathrm{UB}_{i}$ & Utility function of the product profile $i$ \\
\hline $\mathrm{UC}_{k}$ & Utility function of the competitive product $k$ \\
\hline $\mathrm{EM}_{j}$ & Environmental impacts of the manufacturing phase per unit of the new product $j$, \\
\hline $\mathrm{EP}_{j}$ & Environmental Impacts of the processing phase per unit of the new product $j$ \\
\hline $\mathrm{ER}_{j}$ & Environmental Impacts of the EOL phase per unit of the new product $j$ \\
\hline$\mu_{j}$ & Costs incurred in the recovery process of the new product $j$. \\
\hline \multicolumn{2}{|l|}{ Functions } \\
\hline$\varphi_{j}\left(t_{j}\right)$ & Discard rate of the new product $j$, as a function of tolerance $t_{j}$, \\
\hline$L_{j}\left(t_{j}\right)$ & Lifecycle of the new product $j$ \\
\hline $\mathrm{AV}_{j}\left(t_{j}\right)$ & Average number of unscheduled repairs and maintenances per unit time for the new product $j$, \\
\hline$E_{j}\left(t_{j}\right)$ & Overall environmental impacts for the new product $j$ \\
\hline$R_{j}\left(t_{j}\right)$ & Reliability of the new product $j$ \\
\hline$\theta_{j}\left(t_{j}\right)$ & Material cost of the new product $j$ \\
\hline$C_{j}\left(t_{j}\right)$ & Economic costs of the new product $j$ \\
\hline $\mathrm{UA}_{j}\left(p r_{j}, t_{j}\right)$ & Utility function of the new product $j$ \\
\hline$f_{j}^{p r}\left(p r_{j}\right)$ & Utility function of price $p r$ for the new product $j$ \\
\hline$\Gamma_{j}^{E}\left(t_{j}\right)$ & Utility function of environmental impacts $E$ for the new product $j$ \\
\hline$\eta_{j}^{R}\left(t_{j}\right)$ & Utility function of reliability $R$ for new product $j$ \\
\hline $\operatorname{MS}_{j}\left(p r_{j}, t_{j}\right)$ & Market share function of the new product $j$ \\
\hline$\delta_{j}\left(t_{j}\right)$ & Manufacturing cost of the new product $j$ \\
\hline$\pi_{j}\left(p r_{j}, t_{j}\right)$ & Profit function of the new product $j$. \\
\hline \multicolumn{2}{|c|}{ Decisions and auxiliary variables } \\
\hline & Takes the value 1 if the level $l$ of the attribute $v$ is selected for the new product $j$ and 0 otherwise, \\
\hline$u_{v l}$ & Part-worth utility of the level $l$ of the attribute $v$ for the new product $j$, \\
\hline$\omega_{0}, \ldots, \omega_{8}$ & Coefficients of the quadratic polynomial functions, \\
\hline$p r_{j}$ & Price of the new product $j$ \\
\hline$t_{j}$ & Tolerance of the new product $j$. \\
\hline
\end{tabular}

\subsection{Environmental impacts}

The environmental impacts were assessed using an environmental measurement tool, known as Environmental Priority Strategies (EPS) in the product development. This tool considers all changes or disturbances in terms of the Environmental Load Unit (ELU), which is defined in euro [40]. If the expected life of the new product $j$ is denoted by $\mathrm{TT}_{j}$, the environmental impacts of the manufacturing phase per unit of the new product $j\left(\mathrm{EM}_{j}\right)$, 
as shown in equation (3.1), is estimated from the environmental impacts of the raw material per weight of the new product $j\left(\alpha_{j}\right)$, and the total quantity of the raw material of the new product $j\left(\operatorname{mass}_{j}\right)$. These impacts are also discounted using the rate $\rho$.

$$
\mathrm{EM}_{j}=\frac{\operatorname{mass}_{j} \alpha_{j}}{(1+\rho)^{\mathrm{TT}_{j}}}, \quad \forall j .
$$

Since an industrial product is composed of numerous materials, the environmental impacts is thus not only related to the raw material, but also to the materials used in the production process (which is no longer part of the final product). Therefore, the environmental impacts of the processing phase per unit of the new product $j\left(\mathrm{EP}_{j}\right)$, as shown in equation (3.2), is calculated from the environmental impacts of the used materials in the production process per weight of the new product $j\left(\beta_{j}\right)$ as well as the total quantity of the materials used in the production process of new product $j\left(\operatorname{proc}_{j}\right)$.

$$
\mathrm{EP}_{j}=\operatorname{proc}_{j} \beta_{j}, \quad \forall j .
$$

Ultimately, the environmental impacts of the EOL phase per unit of the new product $j\left(\mathrm{ER}_{j}\right)$, is linked to the product recovery at the end of its life, as displayed in equation (3.3). EOL-related environmental impacts per weight of the new product $j\left(\gamma_{j}\right)$ are derived from disassembling the product and recovering the parts. If the expected life of the new product $j$ is denoted by $\mathrm{TT}_{j}$, these impacts are also discounted using the rate $\rho$.

$$
\mathrm{ER}_{j}=\frac{\operatorname{mass}_{j} \gamma_{j}}{(1+\rho)^{\mathrm{TT}_{j}}}, \quad \forall j .
$$

Total environmental impacts $E_{j}$, should be adjusted by the $j$-th product life $L_{j}$, which is affected by the discard rate $\varphi_{j}$. Accordingly, these impacts are calculated from equation (3.4).

$$
E_{j}=\frac{\mathrm{TT}_{j}}{L_{j}\left(\varphi_{j}\right)}\left(\mathrm{EM}_{j}+\mathrm{EP}_{j}+\mathrm{ER}_{j}\right), \quad \forall j
$$

\subsection{Product reliability}

Reliability of the new product $j\left(R_{j}\right)$, can be estimated by an exponential function as described in the literature. The reliability of most industrial products is construed as a function of the life $L_{j}$, and the average number of unscheduled repairs and maintenances per unit time for the new product $j\left(\mathrm{AV}_{j}\right)$, both of which are a function of the discard rate $\varphi_{j}$. Therefore, according to [21], this variable is calculated as follows.

$$
R_{j}=e^{\left(-\mathrm{AV}_{j}\left(\varphi_{j}\right) L_{j}\left(\varphi_{j}\right)\right)}, \quad \forall j .
$$

\subsection{Development of cost models}

It is noteworthy that the product reliability declines over time by the growth of $\mathrm{AV}_{j}$. Designing a reliable product will raise a company's production costs because the reliability is contingent not only on the production system but also on the type of raw materials. Therefore, according to [21], the material cost of the new product $j\left(\theta_{j}\right)$ can be considered as a function of $R_{j}$. Therefore,

$$
\theta_{j}=H_{j}+Z_{j}\left(1-R_{j}\left(\varphi_{j}\right)\right)^{-a}, \quad \forall j .
$$

In the above equation, $H_{j}>0, Z_{j}>0, a>0$ show the fixed and variable manufacturing costs of materials per unit product $j$, respectively. The exact manufacturing cost of the new product $j\left(\delta_{j}\right)$, as described in the literature, is estimated as a reciprocal function of material costs per weight of material mass $\theta_{j}$, the total mass of the material $\operatorname{mass}_{j}$, input tolerance $t_{j}$, and the level of discard rate $\varphi_{j}$, as shown in equation (3.7).

$$
\delta_{j}=\frac{\operatorname{mass}_{j} \theta_{j}+\frac{1}{\boldsymbol{t}_{j}}}{1-\varphi_{j}\left(\boldsymbol{t}_{\boldsymbol{j}}\right)}, \quad \forall j .
$$


According to these input variables (manufacturing $\operatorname{cost} \delta_{j}$, reliability $R_{j}$, and ecological impacts $E_{j}$ ), which are inserted in the objective function in the equation (3.15), the tolerance value is obtained as an output variable. Although manufacturers may make profit from recovering industrial products, recovering also incurs certain costs, which are greater than the cost of raw materials. Costs incurred in the recovery process for the new product $j\left(\mu_{j}\right)$, are computed as follows:

$$
\mu_{j}=r_{j} s_{j}, \quad \forall j
$$

where $r_{j}$ is the weight of parts to be recovered, and $s_{j}$ is the recovery cost per weight of the new product $j$, which must be estimated before delivering a product to the recovering service provider. The recovery cost is set by the recovering service provider. If the expected life of the new product $j$ is denoted by $\mathrm{TT}_{j}$, the manufacturing and recovering costs are adjusted by the product life of the new product $j$, and the total cost is computed as follows:

$$
C_{j}=\frac{\mathrm{TT}_{j}}{L_{j}\left(\varphi_{j}\right)}\left(\delta_{j}+\mu_{j}\right), \quad \forall j
$$

\subsection{Conjoint analysis}

Conjoint analysis is conducted to capture consumer preferences for a product by estimating the part-worth utilities for each level of product attributes [6]. Therefore, according to the survey, the utility functions of products were estimated as follows:

$$
\mathrm{UA}_{j}=\left(\sum_{v=1}^{V} \sum_{l=1}^{L_{v}} x_{j v l} u_{v l}\right)+f_{j}^{p r}+\Gamma_{j}^{E}+\eta_{\mathbf{j}}^{R}, \quad \forall j .
$$

In this equation, $\mathrm{UA}_{j}$ is the utility of the new product $j ; u_{v l}$ is the part-worth utility of the $l$-th level of the $v$-th attribute; $f_{j}^{p r}$ is the utility function of the price of the new product $j ; \Gamma_{j}^{E}$ is the utility function of environmental impacts of the new product $j ; \eta_{j}^{R}$ is a utility function of product reliability of the new product $j$; and $V$ and $L_{v}$ are the number of attributes and the levels of the $v$-th attribute, respectively. Also, $x_{j v l}$ is a dummy variable, which is 1 when the $l$-th level of the $v$-th attribute is selected for the product $j$, and 0 otherwise. Also, because some product attributes in this study are continuous, a curve fitting technique is used to estimate the utility functions, as described below:

$$
\begin{array}{rlrl}
f_{j}^{p r} & =\omega_{0}+\omega_{1} p r_{j}+\omega_{2} p r_{j}^{2}, & & \forall j \\
\Gamma_{j}^{E}=\omega_{3}+\omega_{4} E_{j}+\omega_{5} E_{j}^{2}, & & \forall j \\
\eta_{j}^{R}=\omega_{6}+\omega_{7} R_{j}+\omega_{8} R_{j}^{2}, & & \forall j .
\end{array}
$$

In the above equations, the values of $\omega_{0}, \ldots, \omega_{8}$ are the coefficients of the quadratic polynomial functions; and $p r_{j}, E_{j}$, and $R_{j}$ are continuous attributes of the new product $j$.

\subsubsection{Development of market share models}

Market share is defined as the share of product sales over a period of time, which is calculated from the utility functions. When purchasing a product, customers tend to consider other alternatives that may provide the highest utility. One of the key computational advantages of the market utility-based choice models is that it accounts for shared effects of all alternatives, so that adding or removing an alternative will equally decrease or increase the probability of selecting other alternatives [43]. The market share model based on utility functions is determined as follows:

$$
\mathrm{MS}_{j}=\frac{e^{\left(\mathrm{UA}_{j}\right)}}{\left(\sum_{i=1}^{I} e^{\left(\mathrm{UB}_{i}\right)}+\sum_{k=1}^{K} e^{\left(\mathrm{UC}_{k}\right)}\right)+e^{\left(\mathrm{UA}_{j}\right)}} \quad \forall j
$$


where $\mathrm{MS}_{\boldsymbol{j}}$ is the probability of selecting the new product $j$ among other products in the market; $\mathrm{UA}_{\boldsymbol{j}}$ is the utility of the new product $j$; $\mathrm{UB}_{\boldsymbol{i}}$ is the utility of the existing product $i$; and $\mathrm{UC}_{\boldsymbol{k}}$ is the utility of the competitive product $k$.

\subsection{Formulation of the profit function}

The optimization formulation can be derived from equation (3.14). In this equation, the $\operatorname{cost} \delta_{j}$ is calculated from equation (3.7); $p r_{j}$ is the price of new product $j ; Q$ is the estimated market potential; and $\mathrm{MS}_{\boldsymbol{j}}$ is the market share of the new product $j$. Therefore, by considering the reliability, environmental impacts, and manufacturing cost as a function of $t_{j}$, the profit function can be optimized based on two variables of $p r_{j}$ and $t_{j}$. It is also solved using the DFGS algorithm [9]. Hence, we have:

$$
\max _{p r_{j}, t_{j}} \pi_{j}=\left(p r_{j}-\delta_{j}\left(\boldsymbol{t}_{\boldsymbol{j}}\right)\right) Q \mathrm{MS}_{j}\left(\boldsymbol{p} \boldsymbol{r}_{\boldsymbol{j}}, \boldsymbol{t}_{\boldsymbol{j}}\right), \quad \forall j .
$$

\subsection{Dynamics-simulation model}

Since analyzing and determining the effects of variable factors is another objective of the article and considering the interdependence of factors, it is necessary to evaluate the dynamic relationships between these factors in the long and short terms. To develop a dynamic model for investigating the relationships between variables, the output of the algorithm proposed in the previous sections was used to determine the optimal values of tolerance and price. As the main inputs of system dynamics, these values are used to evaluate the relationship of design factors, reliability, and sustainability with customer satisfaction. A typical procedure for modeling system dynamics is to (1) identify and define the problem, (2) portray systems, (3) develop a computer simulation, (4) illustrate the outcomes, and (5) define potential policies [8].

\section{Case Study}

The proposed methodology was used in the design of a computer case. The main objective of the previously described approach is to determine an optimal tolerance, and pricing strategy that will maximize the manufacturer's profit. To estimate the optimal tolerance, first, we surveyed Iran in an attempt to explore customer preferences about the computer. In this survey, many respondents answered questions about product attributes to evaluate the relationship of price, reliability, and environmental impacts with tolerance, and profit optimization. Then, to assess consumer preferences for a product, the part-worth utility model was used for each level of product attribute.

\subsection{Discard rate}

To discover the discard rate of the new product $j\left(\varphi_{j}\right)$, the experiments are designed by considering 500 input tolerances in the range of 0.004 to $2 \mu \mathrm{m}$ for each running of the Monte Carlo simulation, which is repeated for a total of 100000 times. Therefore, the various values of $\varphi_{j}$ were computed as a function of $t_{j}$, and represented by equation (4.1).

$$
\varphi_{j}\left(t_{j}\right)=\left\{\begin{array}{ll}
0 & t_{j}<0.15 \\
0.9791 \times\left(1+e^{\left(-0.2823-\log \left(t_{j}\right)\right)} / 0.3186\right)^{-1} & t_{j}>0.15
\end{array}\right\}, \quad \forall j .
$$

\subsection{Conjoint analysis for computer}

In this study, six attributes of the computer were identified to perform conjoint analysis. Data were collected via online surveys. For this purpose, computer buyers in different cities of Iran answered questions about computer features, and the results were used for the construction of the market demand models. The survey was conducted online on 250 respondents who had the experience of using computers. Three features that matched the tolerance and profit optimization characteristics, including price, reliability, and environmental impacts, were questioned. Price levels were set based on the computer market of Iran discretely. 
TABle 3. Product attributes and attribute levels of computer.

\begin{tabular}{llll}
\hline \hline Attributes & Level 1 & Level 2 & Level 3 \\
\hline Price & 400 & 500 & 600 \\
Recoverability & 0 & 43 & 67 \\
Reliability & 40 & 39 & 55 \\
Storage space & 0.5 & 1 & 2 \\
Screen resolution & $768 \times 1024$ & $80 \times 1280$ & $1536 \times 2048$ \\
Screen size & 7 & 10 & - \\
\hline
\end{tabular}

TABLE 4. Coding levels of storage space and screen resolution with dummy variables.

\begin{tabular}{llllll}
\hline \hline Storage space & $x_{41}$ & $x_{42}$ & Screen resolution & $x_{51}$ & $x_{52}$ \\
\hline $0.5 \mathrm{~GB}$ & 1 & 0 & $768 \times 1024$ & 1 & 0 \\
$1 \mathrm{~GB}$ & 0 & 1 & $80 \times 1280$ & 0 & 1 \\
$2 \mathrm{~GB}$ & 0 & 0 & $1536 \times 2048$ & 0 & 0 \\
\hline
\end{tabular}

The price levels were estimated in the range of $\$ 400, \$ 500$, and $\$ 600$. Reliability levels was set at three levels $(40,39$, and $55 \%)$. Since information on environmental impacts is not widely available in the specifications of computers on the market, another criterion was adopted to illustrate this feature. For this reason, criteria such as ease of comprehension, accuracy, environmental impacts, measurability on a continuous scale, and respondents' clarity about other computer attributes such as reliability were taken into account. Accordingly, the recoverability attribute was identified as important, which should be demonstrated at three discrete levels. Therefore, for each computer option, its recoverability attribute was set at three levels (0, 43, and 67). Finally, the user's preferences for the recoverability attribute were collected and the part-worth utility of each feature was identified. In the optimization model, which will be analyzed in the following sections, the recovery feature is interpreted as environmental impacts and rated on a scale of $0-100$.

The additional attributes in the choice scenarios include storage space, screen resolution, and screen size, for which three separate levels $(40,39$, and $55 \%$ ) were considered. These attributes are not directly related to the research goals, but since they are part of a computer purchasing decision in the real world and may help evaluate the tastes and requirements of respondents, they were accounted for in the conjoint analysis. Discrete values of storage space of computers based on the market were set at $0.5,1$, and $2 \mathrm{~GB}$. The screen resolution, including $768 \times 1024,800 \times 1280$, and $1536 \times 2048$, and finally, the screen size feature, including 7 inches and 10 inches, were specified. Six important product attributes and their corresponding levels, which were defined based on market information, are shown in Table 3.

\subsubsection{Determining utility functions of the computer}

A dummy variable regression method was applied to compute the utility functions of each attribute. Each product attribute consists of many dummy variables for the attribute levels. If an attribute has $l$ levels, it is coded with $l-1$ dummy variable, so that the value of a dummy variable is 1 or 0 . For example, the attribute levels of storage space and screen resolution are coded as Table 4.

After coding the product profiles with dummy variables, multiple regression analysis was carried out to estimate the coefficients of the utility functions. The results are shown in Table 5 .

In this table, $x_{11}$ and $x_{12}$ are dummy variables of price, $x_{21}$ and $x_{22}$ are dummy variables of recoverability, $x_{31}$ and $x_{32}$ are dummy variables of reliability $x_{41}$ and $x_{42}$ are dummy variables of storage space. $x_{51}$ and $x_{52}$ are dummy variables of screen resolution, and $x_{61}$ is the dummy variable of screen size. 
TABLE 5. Coefficients of utility functions for the market.

\begin{tabular}{llllllllllll}
\hline \hline Regression constant & $x_{61}$ & $x_{52}$ & $x_{51}$ & $x_{42}$ & $x_{41}$ & $x_{32}$ & $x_{31}$ & $x_{22}$ & $x_{21}$ & $x_{12}$ & $x_{11}$ \\
\hline 3.05 & -0.48 & -0.5 & -0.29 & -0.5 & -0.2 & -0.8 & -0.58 & -0.8 & -0.2 & 0.16 & 0.57 \\
\hline
\end{tabular}

TABLE 6 . The generated parameters according to the uniform distribution

\begin{tabular}{llllll}
\hline \hline Parameters & Value & Units & Parameters & Value & Units \\
\hline$\alpha_{j}, \beta_{j}, \gamma_{j}$ & $\sim U(-1.01,1.01)$ & $\begin{array}{l}\text { Dollars per } \\
\text { kilogram }\end{array}$ & $s_{j}$ & $\sim U(0,10)$ & $\begin{array}{l}\text { Dollars per } \\
\text { kilogram }\end{array}$ \\
$H_{j}$ & 0 & $\begin{array}{l}\text { Dollars } \\
Z_{j}\end{array}$ & $Q$ & 25 & Million \\
$\operatorname{mass}_{j}$ & 0.6170 & Dollars & $\rho$ & $\sim U(0,1)$ & Unit-less \\
$\operatorname{proc}_{j}$ & $\sim U(0,0.6)$ & Kilogram & $r_{j}$ & $\sim U(0,0.6170)$ & Kilogram \\
\hline
\end{tabular}

The recoverability attribute is not affected by tolerance design variables. Instead, the environmental factor measured in ELU can be utilized. In this case, it is presumed that consumers evaluate the recoverability attribute in terms of the environmental friendliness score $E_{j}(t)$, which is a function of the input tolerance and is derived from ELU measurement unit. The range of ELU values for different input tolerances is scaled in the range of 0-100\%. With this normalization factor, the tightest tolerance with the lowest ELU corresponds to the utility with $100 \%$ recoverability, and the widest tolerance with the highest ELU tolerance corresponds to the utility with $0 \%$ recoverability. In this study, six attributes contribute to the utility of the computer, three of which are related to the tolerance design decisions: price, reliability, and environmental friendliness. Since the conjoint analysis yields discrete estimates for variables that are treated as continuous in the optimization, a curve fitting method is used to estimate part-worth utility values based on [4]; for example, estimating the part-worth utility of $40 \%$ reliability is done by interpolating between the values related to $23 \%$ and $57 \%$. The other three attributes, storage space, screen resolution, and screen size, are treated as constant in this study.

$$
\begin{aligned}
f_{j}^{p r} & =1.122-1.2 \times 10^{-5} p r_{j}-2.3 \times 10^{-5}\left(p r_{j}\right)^{2} \\
\Gamma_{j}^{E} & =0.522-8.2 \times 10^{-5} E_{j}\left(\boldsymbol{t}_{\boldsymbol{j}}\right)-3.63 \times 10^{-7}\left(E_{j}\left(\boldsymbol{t}_{\boldsymbol{j}}\right)\right)^{2} \\
\eta_{\boldsymbol{j}}^{R} & =3.82-8.015 \times 10^{-4} R_{j}\left(\boldsymbol{t}_{\boldsymbol{j}}\right)-3.536 \times 10^{-5}\left(R_{j}\left(\boldsymbol{t}_{\boldsymbol{j}}\right)\right)^{2}
\end{aligned}
$$

where $f_{j}^{p r}$ is the utility function of the price for the new product $j, \Gamma_{j}^{E}$ is the utility function of the environmental impacts, which is a function of tolerance, and $\eta_{j}^{R}$ is the utility function of reliability for the new product $j$, which is a function of tolerance. In this case study, five competitive computers were identified in the market. The price, reliability, recoverability, and other attributes of competitive products are listed in Appendix B.

\subsection{Optimization results}

The optimization problem have been carried out according to the amount of the parameters that their details are reported in Table 6 . In light of the above, the results of solving the optimization problem for the computer market in Iran are presented in Table 7.

\subsection{Dynamics-simulation model and the relationships between variables}

Therefore, the system dynamics model was developed to identify and explain systemic relationships of reliability factors, product design, and sustainability with customer satisfaction, and understanding the behavior over the study period (48 months), as shown in Figure 2. 
TABLE 7. Optimization results of new computer.

\begin{tabular}{lll}
\hline \hline Variables & Value & Units \\
\hline$t_{j}$ & 0.23 & $\mu \mathrm{m}$ \\
$p r_{j}$ & 412 & Dollars \\
$\mathrm{MS}_{j}$ & 7.1 & $\%$ \\
$D_{j}$ & 1.86 & Million \\
$\pi_{j}$ & 357 & Millions of dollars \\
\hline
\end{tabular}

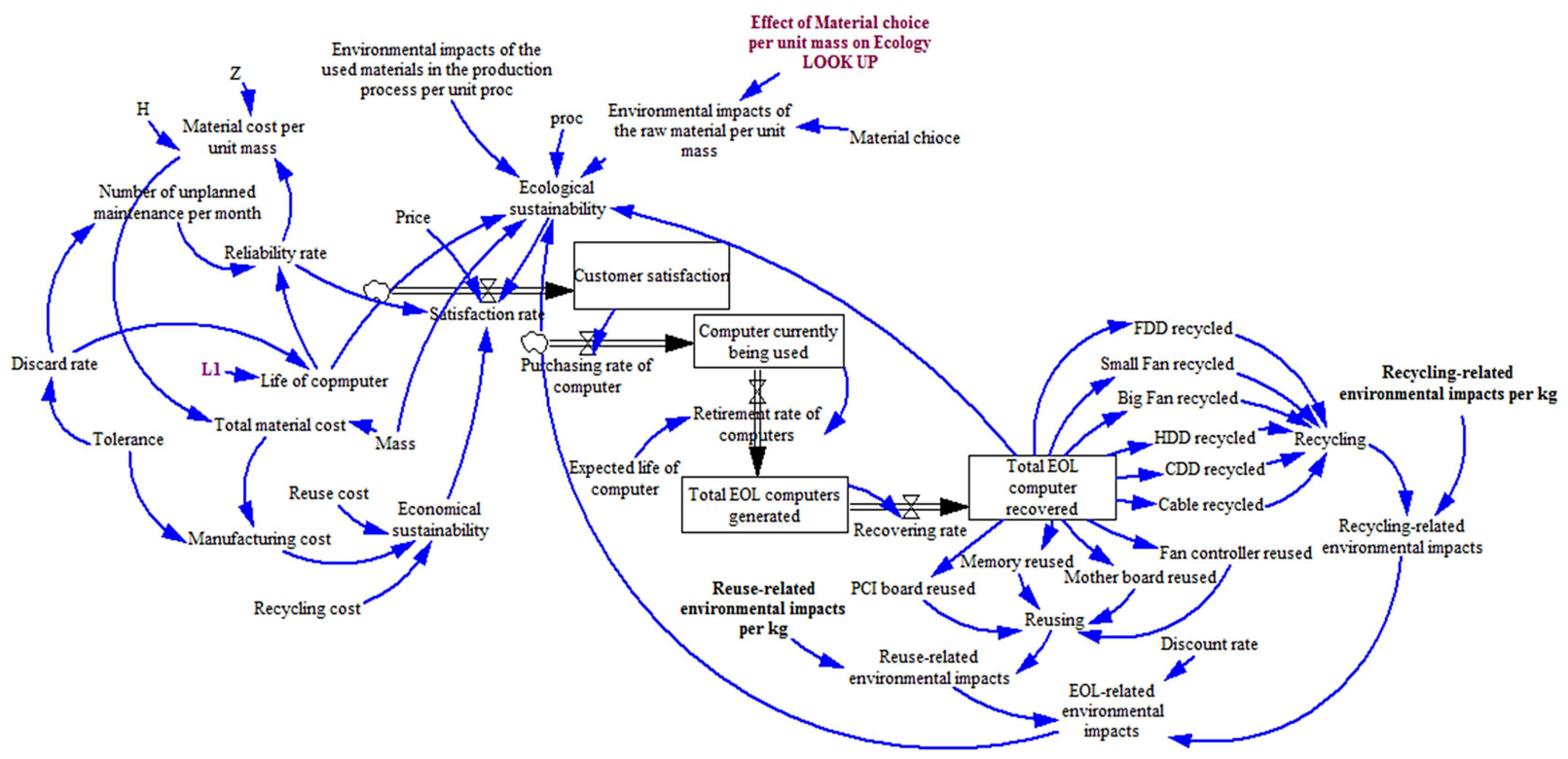

Figure 2. System dynamics diagram.

As shown in Figure 2, tolerance, as a key design factor, is indirectly related to reliability, and sustainability factors (e.g., ecological and economical sustainability). Material choice as another design decision directly affects the environmental costs. A key component that relates design decisions to the resilience-related factor is the discard rate. A discard rate, which is specified by the design tolerances, is any measurement that can influence the way a product is perceived by the customers. It affects, in turn, the number of unplanned maintenance per month, and the product life. Many of these attributes directly or indirectly affect customer satisfaction, which have a significant role in the demand for current and future products. Several factors can also influence the ecological impacts of the product, including material choice, end-of-life recovery strategies, and production processes, which might shorten the product life.

Production cost is the sum of factors such as material cost per gram, the total mass of material, the input tolerances, and the discard rates. Thus, the formulated model showed the interrelationships of these resiliencerelated design decisions and societal goals. The first component was the design decision "tolerances", which ultimately mapped customer satisfaction and sustainability impacts. As a design method, this mapping can assist designers to gain a clear picture of their decisions' impacts early in the design process. For more elaboration, based on the purchasing rate of computers, the number of computers used is considered to enhance customer satisfaction. After prolonged usage, the state of used computers will change into disposed and recovered computers, since they are outdated and no longer able to run up-to-date software. 


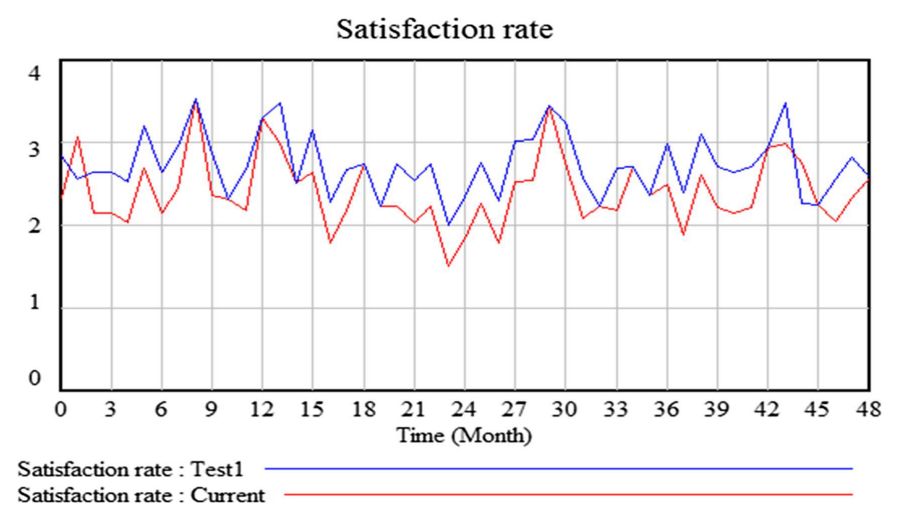

FIGURE 3 . The behavior of customer satisfaction variable in reference condition and exclusion of product life variable (blue).

According to the retirement rate and expected life, some of the used computers are removed, and waste computers are flowing to recover at a certain recovery rate. The processing techniques proposed in this paper are recycling and reusing. As noted by [15], these techniques are the best for computers. According to the [15], and the results of processing methods in the bill of materials (BOM) for a computer case study (48 usage months), It is observed that the \#1 fan controller, \#3 PCI board, \#13 memory, and \#14 motherboard have been selected for reuse due to their low reuse cost. In contrast, \#4 HDD, \#5 FDD, \#6 CDD, \#8 big fan, and \#10 small fan are recycled due to their negative recycling costs. In addition, it is found that \#2 cable is recycled, even though the recycling costs are not negative. In this paper, the system dynamics model is used to simulate trade-offs between customer satisfaction, and factors of product design, reliability, and sustainability. To define key variables, the data are primarily derived from various related sources. Some other data was obtained from the conjoint estimations. The corresponding equation of each variable is mentioned in Appendix A.

\section{Model TESTing}

The validity of the proposed model should be assessed using some tests after identifying all variables and stock-flow diagrams and before applying the analysis model. In this study, the validity of the model was examined by a test, which is described in the following section.

\subsection{Boundary-adequacy test}

The main question of this test is whether the important concepts on the problem have been considered within the model or not. For this purpose, key variables were identified for the proposed model. Then, the model behavior was investigated after the elimination of boundary assumptions. Therefore, by removing one of the key variables (i.e., product life), its impact on the model, and the resulting changes were investigated. Accordingly, the model output with behavior patterns of the reference condition was evaluated for the variables of reliability rate, satisfaction rate, economical sustainability, and manufacturing costs. The test results showed a significant difference by eliminating the product life variable. The test results are displayed in Figures 3-6.

\section{Simulation Results}

After conducting the validation tests, it is essential to run the model simulation. A conventional tool to illustrate the results of system dynamics models is to investigate the behavior of key variables, and compare them with possible scenarios. In this paper, a "current status" indicates the running of the model with the data 


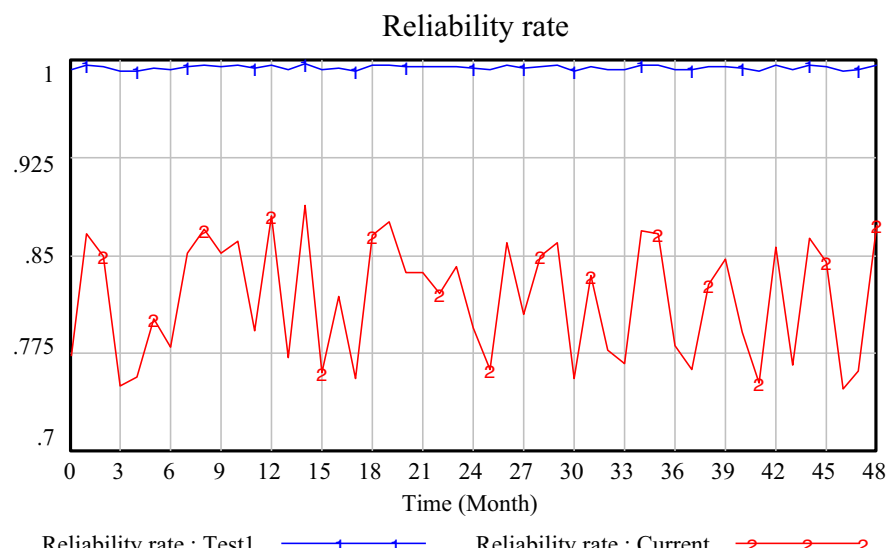

FIgURE 4. The behavior of reliability variable in reference condition and exclusion of product life variable (blue).

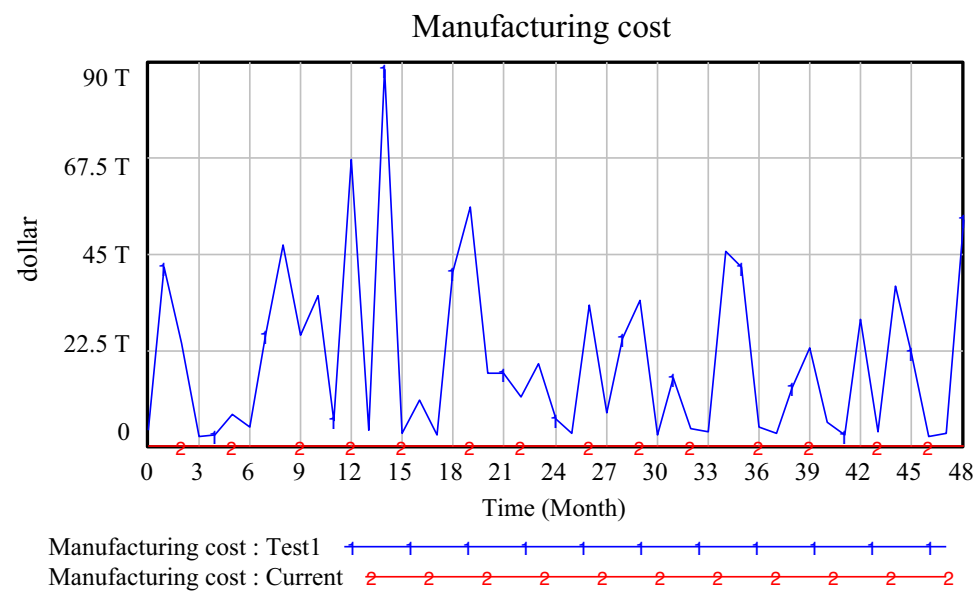

FIGURE 5. The behavior of production cost variable in reference condition and the exclusion of product life variable (blue).

shown in Tables 6 and 7. Once the current status is set, everyone can change the parameters of the key variables to create scenarios.

\subsection{Scenario of tolerance increase}

After designing the model, and ensuring its validity, the results of running the model are investigated in the form of a tolerance increase scenario in this section. To determine different policies, it is necessary to explore how design factors, such as tolerance affects other variables. For example, when the designer uses two different values for tolerances, the sustainability and the reliability of the product, as key factors, may be affected, which will influence customer satisfaction, in the computer market.

In this respect, two different tolerance values are used, and the first and second values were set at 0.23 and $0.92 \mu \mathrm{m}$, respectively. The simulation results of the main variables are as follows: 


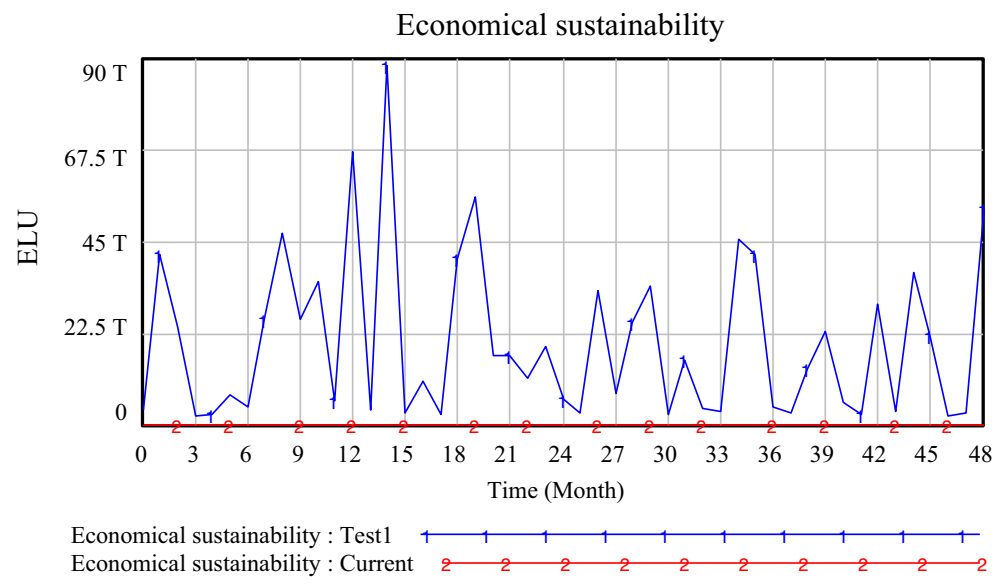

FIGURE 6 . The behavior of ecological sustainability in the reference condition and the exclusion of product life variable (blue).

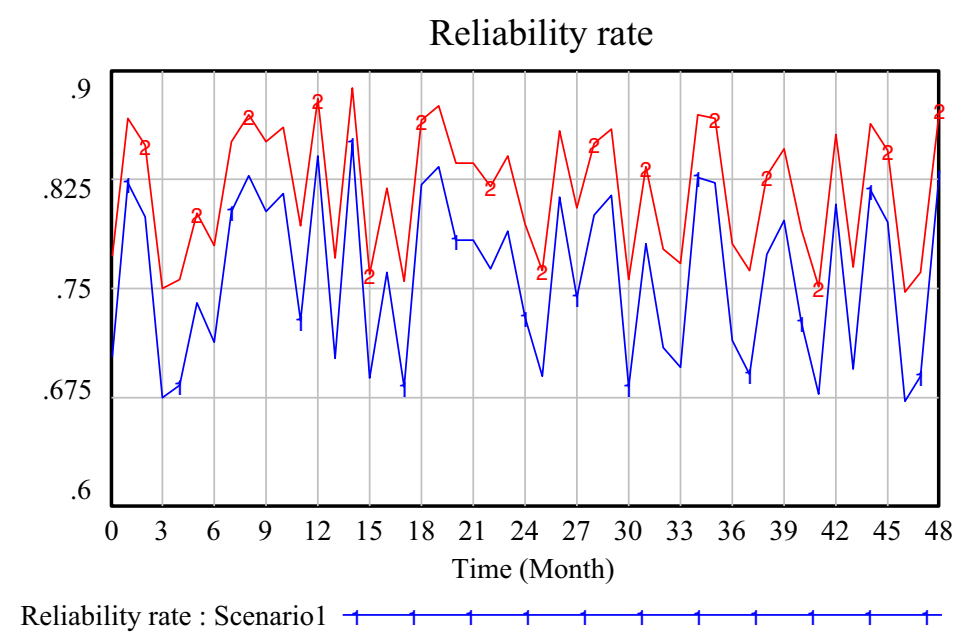

FiguRE 7. Comparing the behavior of reliability under two different tolerance values.

\subsubsection{Reliability comparison}

Figure 7 shows the reliability of the product after tolerance increase and its comparison with the reference condition. Thus, as shown in the graphs, higher reliability of the product is associated with tighter tolerances during the expected life of the product ( 48 months) (blue line).

\subsubsection{Comparison of ecological sustainability}

Figure 8 displays ecological sustainability or environmental costs after tolerance increase and compares it with ecological sustainability at the reference condition. It is clear that with tolerance increase, ecological sustainability reaches its highest level during the expected life of the product ( 48 months) (blue line). 


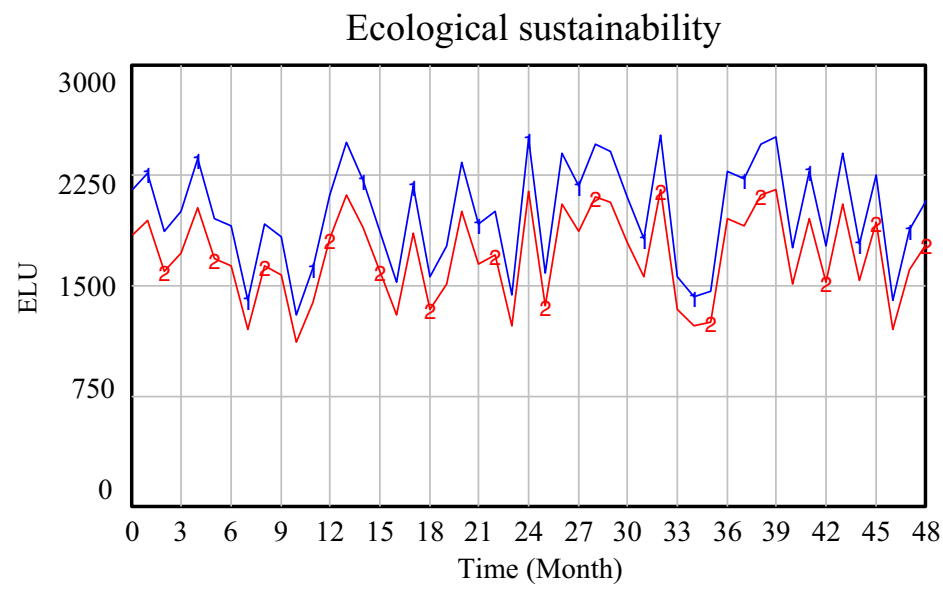

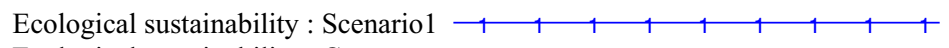
Ecological sustainability: Current $\begin{array}{lllllllllllll}2 & 2 & 2 & 2 & 2 & 2 & 2 & 2 & 2 & 2\end{array}$

FiguRE 8. Comparing the behavior of ecological sustainability under two different tolerance values.

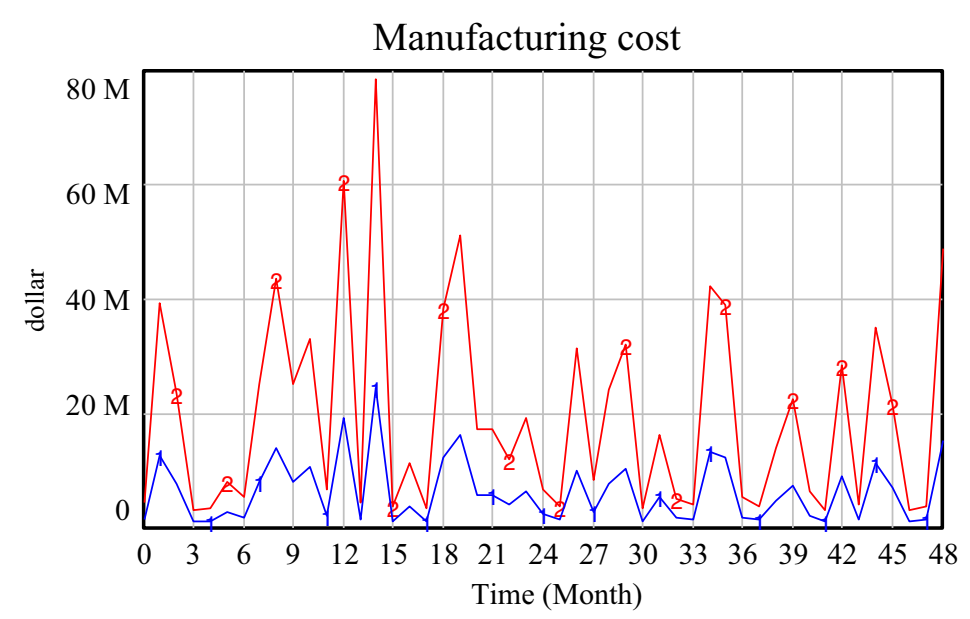

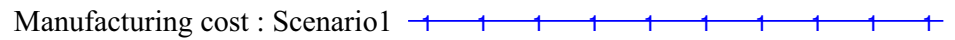

Manufacturing cost : Current $\begin{array}{lllllllllll}2 & 2 & 2 & 2 & 2 & 2 & 2 & 2 & 2 & 2 & 2\end{array}$

Figure 9. Comparing the behavior of manufacturing costs under two different tolerance values.

\subsubsection{Comparison of production costs}

Figure 9 illustrates manufacturing costs, after tolerance increase, and compares it with manufacturing costs at the reference condition. As can be seen, by increasing tolerance, the manufacturing costs will fall to its lowest level during the expected life of the product (48 months) (blue line).

\subsubsection{Comparison of customer satisfaction}

Figure 10 shows customer satisfaction after tolerance improvement and its comparison with the customer satisfaction at the reference condition. As shown in Figure 11, with tolerance increase, customer satisfaction falls to its lowest level during the expected life of the product ( 48 months) (blue line). 

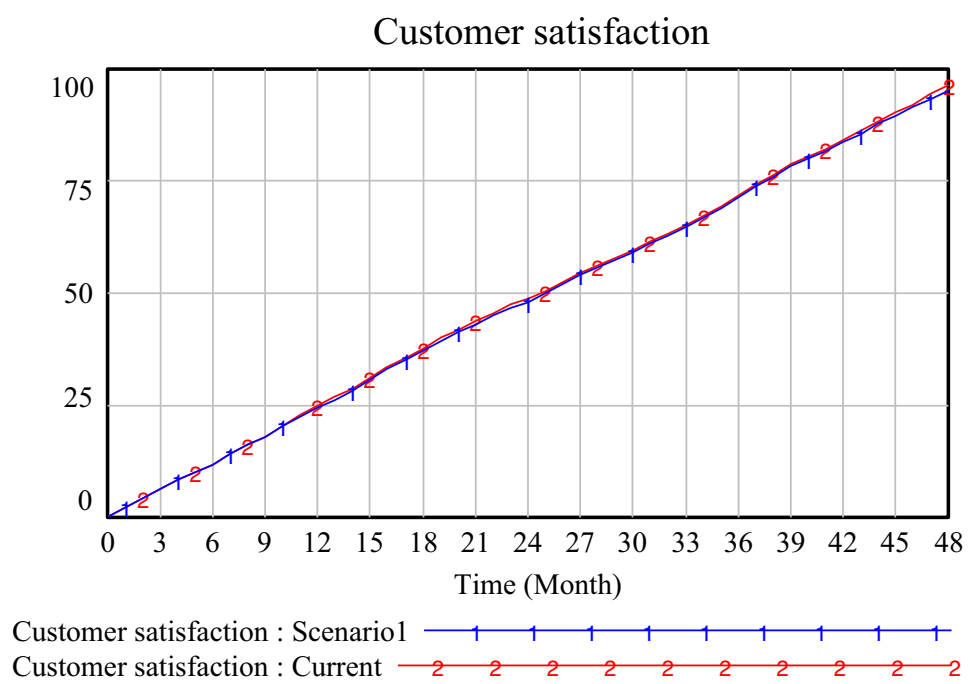

FiguRE 10. Comparing the behavior of customer satisfaction under two different tolerance values.

Thus, as shown in the graphs, lower ecological costs, higher reliability, and higher customer satisfaction are associated with tighter tolerances. The nature of the relationship between design decisions, product reliability, sustainability, and customer satisfaction reflects a trade-off, which helps decision-makers reach more informed decisions.

\subsection{Scenario of material quality decrease}

Using different qualities for materials may affect sustainability and the reliability of the product, which in turn influences customer satisfaction in the computer market. In this respect, two different quality materials have been used in this study: one for high-quality material and for the other for low-quality material. The simulation results for the main variables are shown below:

\subsubsection{Reliability comparison}

Figure 11 shows product reliability after quality degradation and its comparison with the reference condition. Thus, as shown, higher reliability of a product is associated with higher quality material during the expected life of the product (48 months) (blue line).

\subsubsection{Comparison of ecological sustainability}

Figure 12 displays ecological sustainability or environmental costs after quality degradation and compares it with ecological sustainability at the reference condition. As shown, with quality degradation, ecological sustainability reaches its lowest level during the expected life of the product (48 months) (blue line).

\subsubsection{Comparison of customer satisfaction}

Figure 13 shows customer satisfaction after quality degradation and its comparison with the customer satisfaction at the reference condition. As shown in Figure 13, with quality degradation, customer satisfaction falls to its highest level during the expected life of the product (48 months) (blue line).

Thus, as shown in the graphs, lower ecological costs, higher reliability, and higher customer satisfaction are associated with lower quality. Using high-quality material may reduce environmental pollution, but it may decrease customer satisfaction due to its high price. For example, both aluminum as a low-quality material and carbon fiber composites as high-quality materials could be used in planes. However, the higher quality material 


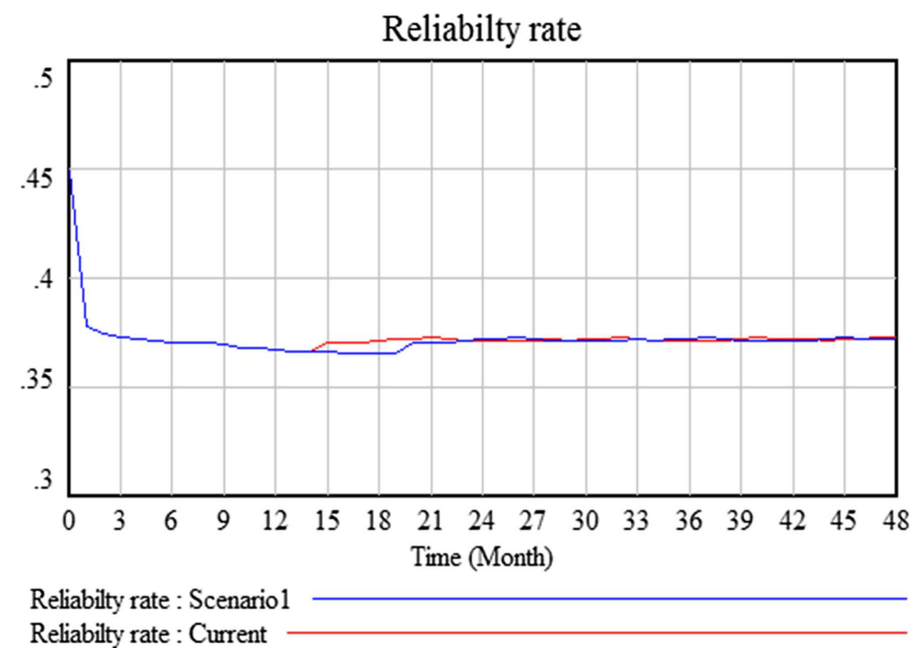

FIgURE 11. Comparing reliability for two different material quality values.

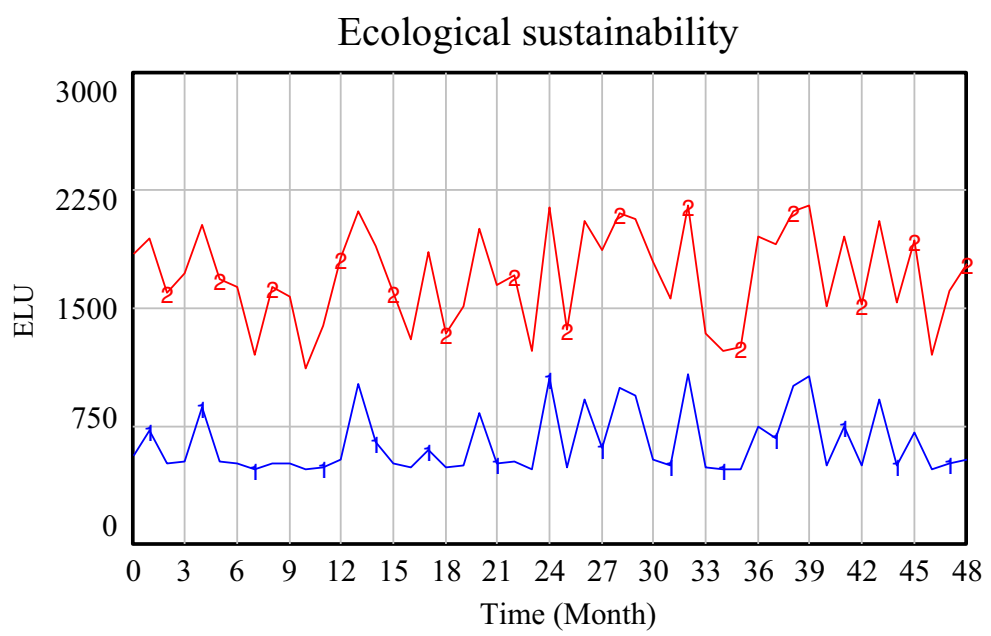

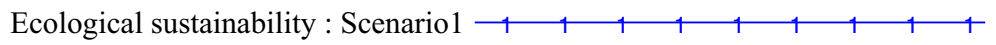

Ecological sustainability : Current $\begin{array}{llllllllllllll}2 & 2 & 2 & 2 & 2 & 2 & 2 & 2 & 2 & 2\end{array}$

FIgURE 12. Comparing ecological sustainability for two different material quality values.

is more expensive and leads to greater environmental pollution. This is also true for many other materials. The nature of relationships between design decisions, product reliability, sustainability, and customer satisfaction reflects a trade-off, which can help decision-makers reach more informed decisions.

\section{Conclusions}

This study proposed a hybrid model for the design process of products such as computers that incorporate variables, including tolerance decisions, product price, sustainability costs, product reliability, and customer satisfaction. The principal findings of this study are as follows: 

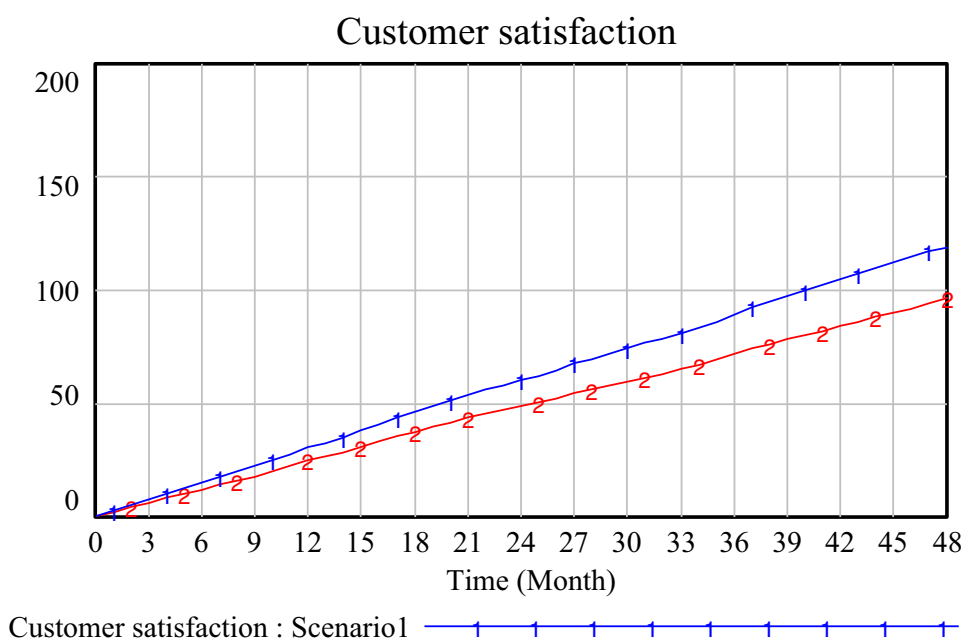

Customer satisfaction : Current $\begin{array}{lllllllllll}2 & 2 & 2 & 2 & 2 & 2 & 2 & 2 & 2\end{array}$

Figure 13. Comparing customer satisfaction for two different material quality values.

- Lower ecological costs, higher reliability, and higher customer satisfaction are associated with tighter tolerances.

- Lower ecological costs, higher reliability, and higher customer satisfaction are associated with lower qualities of materials.

Determining appropriate tolerance is a key factor in the design process of many products. In some products, e.g., computers, precision manufacturing and assembly process are critical. For some products, such as small consumer electronics, tolerance decisions can even lead to the imperfect appearance or poor functionality of the product. Regardless of the product type, tolerance decisions are often essential for a sustainable economic business. This becomes more important as consumers and manufacturers are increasingly required to comply with environmental issues. The optimization-simulation approach presented in this paper allows designers to understand how tolerance decisions can be utilized as a trade-off between sustainability costs, reliability, and customer satisfaction. In this approach, first, the optimal values of tolerance and price were determined by conjoint analysis in terms of profit maximization and market share. These optimal values are added to the system dynamics model to evaluate the relationships of sustainability and product reliability with customer satisfaction. Although the optimization model can help make important design decisions, it fails to model key aspects of product design dynamics. The example of computer design illustrated that the system dynamics simulation can provide deeper insights into feedback loops, tradeoffs, and input-output relationships.

\subsection{Theoretical implications}

Previous studies have attempted to minimize costs based on a set of predetermined tolerance values but failed to provide a profound analysis of how sustainability and reliability factors influence demand and customer satisfaction. In other words, as far as demand and market share functions are concerned, sustainability and reliability factors are not formulated according to the product tolerance features. The present study aimed to bridge this gap in previous studies on costs and tolerances, by painting a clear picture of tolerances impacts on sustainability and reliability factors. In practice, the results of the model can help designers make more informed decisions. The main rationale behind exploring these relationships is the designer's need to better 
identify customer preferences and measure customer satisfaction with a product. As noted in previous studies, utility is a measure of preference for a product.

\subsection{Practical implications}

The proposed model can be used to address practical problems in a real case. In practice, the results of the model can help designers make more informed decisions. Further, the proposed model can help designers determine appropriate design factors such as reliability, price, and environmental impacts to meet the desired level of customer demand. The designers can then employ appropriate tolerance and price to obtain long-term sustainability benefits. This type of modeling could be applied to both computer products and other industrial products. This is a comprehensive framework because it considers all of sustainability factors and their details. These factors are present in all industries, but their amount and importance may differ. Using such a method, designers can change the variables of models to create different scenarios. This approach can help decisionmakers understand the trade-off between resilience, sustainability, and customer satisfaction, and subsequently make more informed decisions.

\subsection{Limitations and directions for future research}

The current study has several limitations that should be considered before the generalization of findings. The data was gathered exclusively from Iranian customers. Thus, future research should expand the customer base to include other regions and cross-culture aspects, and explore similarities and contrasts between various relationships. In this paper, demographical impacts (e.g., male and female gender or income level) were not considered, and only the overall effects were taken into account. An extended analysis could help identify moderating impacts (e.g., age, sexual orientation, and race), and therefore provide deeper insight into online shopping. In the actual product development, there are countless tolerances with different characteristics. Therefore, it is almost impossible to estimate these tolerances with a simple formula. Hence, for actual analysis, it is recommended that future studies use the "big data analysis technique" in parallel. The above approach only considers the interactions of tolerance factor with sustainability and product reliability, and other design factors such as robustness and product complexity are neglected. Product complexity can account for the number of parts and functions, and increased complexity can cause lower robustness and increased manufacturing costs. It is recommended to incorporate more detailed design factors in the model, and to determine how these decisions can have an effect on sustainability, and customer satisfaction. Further, we did not examine other resilience factors such as, product restoration, which can be added to the proposed model in future works. Giahi et al. [11] also revealed that product restoration can be considered as a resilience factor. Since the present study focused on reliability factors, considering other significant factors warrants another research.

Additionally, different simulation tools could also be used which are capable of evaluating the environmental sustainability of circular products systems. Considering circular product systems instead of linear product systems is a big step to get closer to the real world [3]. Researchers can also utilize uncertainty programming such as robust, fuzzy, possibilistic, and possible techniques as described by [26,27]. For future research, it is also recommended to use other non-parametric regression models for the conjoint analysis of qualitative and quantitative data and improve the estimations. Multivariate Adaptive Regression Splines (MARS) and Conic Multivariate Adaptive Regression Splines (CMARS) [13,32] are forms of non-parametric regression analysis for building high-dimensional and nonlinear multivariate functions that have been applied in many fields of science, engineering, technology, finance, and control design in recent years. Since these regression models are not capable of handling data uncertainty, we encourage researchers to take into account the uncertainty into MARS and CMARS, and robustify them through Robust Optimization [5, 12,30-32,41]. In addition, we suggest a fuzzy conceptual framework into MARS to deal with those uncertainties [7,36,42]. Moreover, given the problem type (i.e., the nonlinearity of the model and NP-hardness of the problem), heuristics and meta-heuristic algorithms $[19,20,28,33]$ can be considered to solve large-sized problems in the optimization approach. 


\title{
Appendix A. Equations of Rate And stock variables
}

\author{
STOCK: \\ Customer satisfaction $=$ INTEG $($ Satisfaction rate, 0.1$)$ \\ INFLOWS: \\ Satisfaction rate $=$ IF THEN ELSE (Ecological sustainability $\leq 1200$, RANDOM UNIFORM \\ $(0.5,1,1)$, RANDOM UNIFORM $(0,0.5,1))+$ IF THEN ELSE (Price $\leq 500$, RANDOM UNIFORM \\ $(0.5,1,1)$, RANDOM UNIFORM $(0,0.5,1))+$ IF THEN ELSE (Reliability rate $\geq 0.3$, RANDOM UNI- \\ FORM $(0.5,1,1)$, RANDOM UNIFORM $(0,0.5,1))$ \\ STOCK: \\ Amount of EOL computers = INTEG (Retirement rate of computers - Recovering rate, 3 ) \\ INFLOWS: \\ Retirement rate of computers $=$ Computer being used/Expected life of computers \\ OUTFLOWS: \\ Recovering rate $=a$ \\ STOCK: \\ The Computer being used = INTEG (Purchasing rate of computer - Retirement rate of computers, 100) \\ INFLOWS: \\ Purchasing rate of computer $=$ SMOOTHI (Customer satisfaction, 6, 1) \\ OUTFLOWS: \\ Retirement rate of computers $=$ Computer being used/Expected life of computers \\ STOCK: \\ Total EOL computers generated = INTEG (Retirement rate of computers - Recovering rate, 3 ) \\ INFLOWS: \\ Retirement rate of computers $=a$ \\ OUTFLOWS: \\ Recovering rate $=c$ \\ STOCK: \\ Total EOL computer recovered $=$ INTEG (Recovering rate, 100) \\ INFLOWS: \\ Recovering rate $=c$

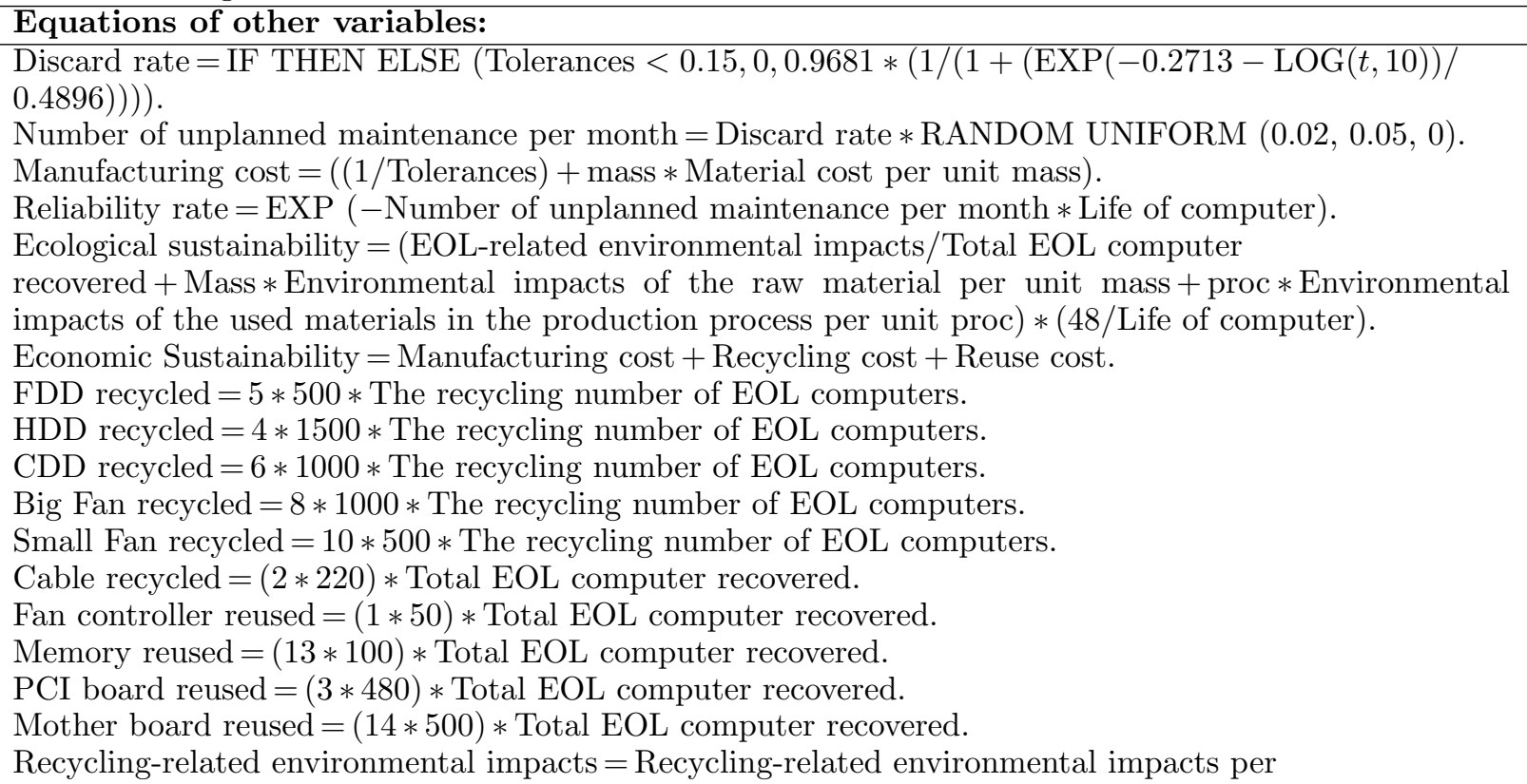


$\mathrm{kg} *$ (Recycling/1000).

Reuse-related environmental impacts $=$ Reuse-related environmental impacts per $\mathrm{kg} *($ Reusing $/ 1000)$.

Effect of Recycling on Ecology = Effect of Recycling on Ecology per kg* (Recycling/1000).

Effect of Reusing on Ecology = Effect of Reusing on Ecology per kg* (Reusing/1000).

EOL-related environmental impacts $=($ Recycling-related environmental impacts + Reuse-related environmental impacts $) /(1+$ Discount rate $) ` 48$.

\section{Equations of functions:}

Effect of Material choice per unit mass on Ecology = Effect of Material choice per unit mass on Ecology LOOK UP(Material choice) $[(1,0)-(6,1)],(6,0.0877193),(5,0.092281),(4,0.10053),(3,0.20456)$, $(2,0.48895),(1,0.40404)$.

Life of computer $=\mathrm{L} 1($ Discard rate) $[(0,0)-(1,40)],(0,40),(0.1129,36),(0.18654,34.0789),(0.231,48)$, $(0.41,27.99),(0.77676,24.364),(0.825688,20.6228),(0.9761,17.5746),(0.9785,15.9605),(1,10.0395)$.

\section{Appendix B. Specifications of COMpetitive COMPUTERS in the MARKet}

\begin{tabular}{lllllll}
\hline & Price & Recovery & Reliability & Storage space & Screen resolution & Screen size \\
\hline Product $a$ & 31 & 0 & 71 & 1 & $1280 \times 800$ & 10 \\
Product $b$ & 430 & 67 & 64 & 1 & $2048 \times 1536$ & 7 \\
Product $c$ & 510 & 50 & 60 & 1 & $2048 \times 1536$ & 10 \\
Product $d$ & 450 & 47 & 68 & 2 & $1280 \times 800$ & 7 \\
Product $e$ & 320 & 40 & 73 & 2 & $2048 \times 1536$ & 10 \\
\hline
\end{tabular}

Acknowledgements. The authors would like to acknowledge the valuable comments and suggestions of the reviewers, which have improved the quality of this paper. The authors also wish to acknowledge the assistance and help of Dr. Reza lotfi in completing the paper.

\section{REFERENCES}

[1] S. Alp and E. Öz, Customer Oriented Product Design with Conjoint Analysis. Springer, Cham (2020) $401-415$.

[2] Y.A. Alamerew and D. Brissaud, Modelling and assessment of product recovery strategies through systems dynamics. Proc. CIRP 69 (2018) 822-826.

[3] F.M. Asif, M. Lieder and A. Rashid, Multi-method simulation based tool to evaluate economic and environmental performance of circular product systems. J. Clean. Prod. 139 (2016) 1261-1281.

[4] R. Aydin, C.K. Kwong and P. Ji, Coordination of the closed-loop supply chain for product line design with consideration of remanufactured products. J. Clean. Prod. 114 (2016) 286-298.

[5] E. Babaee Tirkolaee, A. Goli, M. Pahlevan and R. Malekalipour Kordestanizadeh, A robust bi-objective multi-trip periodic capacitated arc routing problem for urban waste collection using a multi-objective invasive weed optimization. Waste Manage. Res. 37 (2019) 1089-1101.

[6] W. Chen, C. Hoyle and H.J. Wassenaar, Decision-based Design: Integrating Consumer Preferences into Engineering Design. Springer Science \& Business Media (2012).

[7] S.K. Das, S.K. Roy and G.-W. Weber, Application of type-2 fuzzy logic to a multiobjective green solid transportation-location problem with dwell time under carbon tax, cap, and offset policy: fuzzy versus nonfuzzy techniques. IEEE Trans. Fuzzy Syst. 28 (2020) 2711-2725.

[8] D.N. Ford and J.D. Sterman, Dynamic modeling of product development processes. Syst. Dyn. Rev.: J. Syst. Dyn. Soc. 14 (1998) 31-68.

[9] J.W. Forrester, Industrial dynamics. A major breakthrough for decision makers. Harvard Bus. Rev. 36 (1958) $37-66$.

[10] J. Forrester, Principles of systems. Allen. Press. Inc. 1 (1968) 51.

[11] R. Giahi, C.A. MacKenzie and C. Hu, Design optimization for resilience for risk-averse firms. Comput. Ind. Eng. 139 (2020) 106122.

[12] A. Goli, H.K. Zare, R. Tavakkoli-Moghaddam and A. Sadeghieh, Application of robust optimization for a product portfolio problem using an invasive weed optimization algorithm. Numer. Algebra Control Optim. 9 (2019) 187.

[13] M. Graczyk-Kucharska, A. Özmen, M. Szafrański, G.W. Weber, M. Golińśki and M. Spychała, Knowledge accelerator by transversal competences and multivariate adaptive regression splines. Cent. Eur. J. Oper. Res. 28 (2020) 645-669.

[14] P.E. Green and V. Srinivasan, Conjoint analysis in consumer research: issues and outlook. J. Cons. Res. 5 (1978) 103-123.

[15] S. Hasegawa, Y. Kinoshita, T. Yamada and S. Bracke, Life cycle option selection of disassembly parts for material-based $\mathrm{CO}_{2}$ saving rate and recovery cost: analysis of different market value and labor cost for reused parts in German and Japanese cases. Int. J. Prod. Econ. 213 (2019) 229-242. 
[16] R. Hochmuth, H. Meerkamm and W. Schweiger, An approach to a general view on tolerances in mechanical engineering. IPD 98 (1998) 65-76.

[17] S. Hoffenson and R. Söderberg, Systems thinking in tolerance and quality-related design decision-making. Proc. CIRP 27 (2015) 59-64.

[18] S. Hoffenson, A. Dagman and R. Söderberg, Tolerance optimisation considering economic and environmental sustainability. J. Eng. Des. 25 (2014) 367-390.

[19] S. Khalilpourazari and S. Khalilpourazary, An efficient hybrid algorithm based on Water Cycle and Moth-Flame Optimization algorithms for solving numerical and constrained engineering optimization problems. Soft Comput. 23 (2019) 1699-1722.

[20] S. Khalilpourazari, S. Soltanzadeh, G.-W. Weber and S.K. Roy, Designing an efficient blood supply chain network in crisis: neural learning, optimization and case study. Ann. Oper. Res. 289 (2020) 123-152.

[21] B. Khara, J.K. Dey and S.K. Mondal, An inventory model under development cost-dependent imperfect production and reliability-dependent demand. J. Manag. Anal. 4 (2017) 258-275.

[22] O. Kramer, D.E. Ciaurri and S. Koziel, Derivative-free optimization. In: Computational Optimization, Methods and Algorithms. Springer, Berlin, Heidelberg (2011) 61-83.

[23] M. Kuzmanovic, M. Martic and M. Vujosevic, Designing a profit-maximizing product line for heterogeneous market. Tehnicki vjesnik 26 (2019) 1562-1569.

[24] S. Lee, Y. Geum, H. Lee and Y. Park, Dynamic and multidimensional measurement of product-service system (PSS) sustainability: a triple bottom line (TBL)-based system dynamics approach. J. Clean. Prod. 32 (2012) 173-182.

[25] L. Liu, Y. Hsu and J. Lin, Sustainable development analysis of design and manufacturing integration: a system dynamics approach. Cog. Eng. 6 (2019) 1682775.

[26] R. Lotfi, Z. Yadegari, S.H. Hosseini, A.H. Khameneh, E.B. Tirkolaee and G.-W. Weber, A robust time-cost-quality-energyenvironment trade-off with resource-constrained in project management: a case study for a bridge construction project. J. Ind. Manag. Optim. 13 (2020). DOI: 10.3934/jimo.2020158.

[27] R. Lotfi, Y.Z. Mehrjerdi, M.S. Pishvaee, A. Sadeghieh and G.-W. Weber, A robust optimization model for sustainable and resilient closed-loop supply chain network design considering conditional value at risk. Numer. Algebra Control Optim. 11 (2021) 221.

[28] A. Martin, V. Gayathri, G. Saranya, P. Gayathri and P. Venkatesan, A hybrid model for bankruptcy prediction using genetic algorithm, fuzzy c-means and mars. Preprint arXiv:1103.2110 (2011).

[29] E.C.L. Muniz and O. Possamai, The complexity of new products: a dynamic model for productivity loss analysis within productive systems. Gest. Prod. 26 (2019) e2372.

[30] A. Özmen and G.W. Weber, RMARS: robustification of multivariate adaptive regression spline under polyhedral uncertainty. J. Comput. App. Math. 259 (2014) 914-924.

[31] A. Özmen, G.W. Weber and İ. Batmaz, The new robust CMARS (RCMARS) method. Vectors. 1 (2010) $362-368$.

[32] A. Özmen, G.W. Weber, İ. Batmaz and E. Kropat, RCMARS: robustification of CMARS with different scenarios under polyhedral uncertainty set. Commun. Nonlinear Sci. Numer. Simul. 16 (2011) 4780-4787.

[33] T. Paksoy, N.Y. Pehlivan and E. Özceylan, Application of fuzzy optimization to a supply chain network design: a case study of an edible vegetable oils manufacturer. App. Math. Model. 36 (2012) 2762-2776.

[34] P.Y. Papalambros and D.J. Wilde, Principles of Optimal Design: Modeling and Computation, 2nd edition. Cambridge Univ. Press, New York (2000) 7 .

[35] J. Peters, Tolerancing the components of an assembly for minimum cost. J. Eng. Ind. 92 (1970) 677-682.

[36] S.K. Roy, S. Midya and G.-W. Weber, Multi-objective multi-item fixed-charge solid transportation problem under twofold uncertainty. Neural Comput. App. 31 (2019) 8593-8613.

[37] S. Siriwardena, G. Hunt, M.F. Teisl and C.L. Noblet, Effective environmental marketing of green cars: a nested-logit approach. Transp. Res. D 17 (2012) 237-242.

[38] F.H. Speckhart, Calculation of tolerance based on a minimum cost approach. J. Eng. Ind. 94 (1972) $447-453$.

[39] M.F. Spotts, Allocation of tolerances to minimize cost of assembly. J. Eng. Ind. 95 (1973) 762-764.

[40] B. Steen, A systematic approach to environmental priority strategies in product development (EPS): version 2000-models and data of the default method. J. Chalmers tek. högsk. (1999) 67.

[41] R. Syah, M. Elveny, M. Nasution and G.W. Weber, Enhanced knowledge acceleration estimator optimally with MARS to business metrics in merchant ecosystem. In: 2020 4rd International Conference on Electrical, Telecommunication and Computer Engineering (2020) 1-6.

[42] E.B. Tirkolaee, A. Goli and G.-W. Weber, Multi-objective aggregate production planning model considering overtime and outsourcing options under fuzzy seasonal demand. In: International Scientific-Technical Conference Manufacturing. Springer, Cham (2019) 81-96.

[43] K.E. Train, Discrete Choice Methods with Simulation. Cambridge Univ. Press (2009).

[44] L. Yao, T. Liu, X. Chen, M. Mahdi and J. Ni, An integrated method of life-cycle assessment and system dynamics for waste mobile phone management and recycling in China. J. Clean. Prod. 187 (2018) 852-862.

[45] L.J. Zeballos, C.A. Mendez and A.P.B. Povoa, Mixed-integer linear programming approach for product design for life-cycle profit. Comput. Ind. Eng. 137 (2019) 106079. 


\section{Subscribe to Open (S20) A fair and sustainable open access model}

This journal is currently published in open access under a Subscribe-to-Open model (S2O). S2O is a transformative model that aims to move subscription journals to open access. Open access is the free, immediate, online availability of research articles combined with the rights to use these articles fully in the digital environment. We are thankful to our subscribers and sponsors for making it possible to publish this journal in open access, free of charge for authors.

\section{Please help to maintain this journal in open access!}

Check that your library subscribes to the journal, or make a personal donation to the $\mathrm{S} 2 \mathrm{O}$ programme, by contacting subscribers@edpsciences.org

More information, including a list of sponsors and a financial transparency report, available at: https://www. edpsciences.org/en/maths-s2o-programme 